\title{
Current status and outlook in the application of microalgae in biodiesel production and environmental protection
}

\author{
Xin Zhang ${ }^{1,2}$, Junfeng Rong ${ }^{3}$, Hui Chen ${ }^{1}$, Chenliu He ${ }^{1}$ and Qiang Wang ${ }^{1}$ * \\ ${ }^{1}$ Key Laboratory of Algal Biology, Institute of Hydrobiology, Chinese Academy of Sciences, Wuhan, China \\ ${ }^{2}$ University of Chinese Academy of Sciences, Beijing, China \\ ${ }^{3}$ SINOPEC Research Institute of Petroleum Processing, Beijing, China
}

\section{Edited by:}

Cherng-Yuan Lin, National Taiwan

Ocean University, Taiwan

\section{Reviewed by:}

Anoop Singh, Denmark Technical

University, Denmark

Umakanta Jena, Desert Research Institute, USA

Liangcheng Yang, The Ohio State University, USA

Abu Yousuf, Shahjalal University of Science and Technology, Bangladesh

\section{*Correspondence.}

Qiang Wang, Key Laboratory of Algal Biology, Institute of Hydrobiology,

Chinese Academy of Sciences,

Wuhan 430072, China

e-mail:wangqiang@ihb.ac.cn
Microalgae have been currently recognized as a group of the most potential feedstocks for biodiesel production due to high productivity potential, efficient biosynthesis of lipids, and less competition with food production. Moreover, utilization of microalgae with environmental purposes $\left(\mathrm{CO}_{2}\right.$ fixation, $\mathrm{NO}_{x}$, and wastewater treatment) and biorefinery has been reported. However, there are still challenges that need to be addressed to ensure stable large-scale production with positive net energy balance. This review gives an overview of the current status of the application of microalgae in biodiesel production and environmental protection. The practical problems not only facing the microalgae biodiesel production but also associated with microalgae application for environmental pollution control, in particular biological fixation of greenhouse gas $\left(\mathrm{CO}_{2}\right.$ and $\left.\mathrm{NO}_{x}\right)$ and wastewater treatment are described in detail. Notably, the synergistic combination of various applications (e.g., food, medicine, wastewater treatment, and flue gas treatment) with biodiesel production could enhance the sustainability and economics of the algal biodiesel production system.

Keywords: microalgae, biodiesel, $\mathrm{CO}_{2}$ capture, biological DeNO${ }_{x}$, wastewater treatment

\section{INTRODUCTION}

Current trends in energy supply and use are simply unsustainableeconomically, socially, and environmentally (International Energy Agency, 2013a). Fossil fuels are at the core of energy demand in the transport and electricity generation sectors and account for most - over $80 \%$ - of global total primary energy supply (TPES) (International Energy Agency, 2013b). After the combustion of fossil fuels, fossil fuel flue gas can contain hundreds of different compounds, such as $\mathrm{CO}_{2}$, nitrogen oxides $\left(\mathrm{NO}_{\mathrm{x}}\right)$, sulfur oxides $\left(\mathrm{SO}_{\mathrm{x}}\right), \mathrm{H}_{2} \mathrm{O}, \mathrm{O}_{2}, \mathrm{~N}_{2}$, unburned carbohydrates ( $\left.\mathrm{CxHy}\right), \mathrm{CO}$, heavy metals, halogen acids, and particulate matter (PM) (Simoneit et al., 2000; Van den Hende et al., 2012). Growing energy demand for fossil fuels comes from worldwide economic growth and development resulting in the sharp accumulation in $\mathrm{CO}_{2}$ and $\mathrm{NO}_{\mathrm{x}}$ emissions, responsible for the majority of greenhouse gas (GHG) emissions worldwide, which bring some irreversible changes to the climate system including global warming. Without decisive action, energy-related GHG emissions will be more than double by 2050 (International Energy Agency, 2013c). This issue has led to the expansion of research and development on alternative energy with renewability and sustainability.

In recent years, renewable energy sources (e.g., hydro, bioenergy, solar, wind, so on) have received lots of attention and have been used by different nations to reduce consumption of fossil fuels and GHG emissions. Based on the report from International Energy Agency in 2013, bioenergy (biomass and biofuels) currently account for $10 \%$ of TEPS compared with hydro energy $2.3 \%$ and others $1 \%$ (geothermal, solar, wind, heat). Compared with other forms of renewable energy, biofuels allow energy to be chemically stored, and also be used in existing engines and transportation infrastructures after blending to various degrees with petroleum diesel (Miao and Wu, 2006b). Based on these evidences, biofuels especially biodiesel will play a more crucial role as an alternative renewable energy in the near future to further diversify the global energy sources and gradually replace the fossil fuels.

The feedstock selection for biodiesel production has evolved from the edible vegetable oils to the non-edible oils, and now focuses on microalgae (Amaro et al., 2011). Microalgae are microscopic photosynthetic organisms that distribute in a wide range of environmental conditions, not only aquatic but also terrestrial. It has been reported that using microalgae for biodiesel production has lots of advantages (Ginzburg, 1993; Dote et al., 1994; Hu et al., 2008; Wang et al., 2008). From inherent characteristics of the alga cell, they have much higher growth rate than other biodiesel feedstock. Many microalgae species have high lipids content or can be induced to accumulate substantial quantities of lipids. Under natural growth conditions, phototrophic microalgae require primarily three components to produce biomass, i.e., water, $\mathrm{CO}_{2}$, and sunlight (Nigam and Singh, 2011). They absorb sunlight, and assimilate carbon dioxide from the air and nutrients from the aquatic habitats (Singh et al., 2011b). They can live in a variety of environmental conditions (freshwater and marine commonly), thus requiring much less land area. Moreover, they can remove $\mathrm{CO}_{2}$ and $\mathrm{NO}_{\mathrm{x}}$ from industrial flue gases by biofixation and be applied to treat wastewater by removal of $\mathrm{NH}_{4}^{+}, \mathrm{NO}_{3}^{-}$, and $\mathrm{PO}_{4}^{3-}$. In addition, algae biodiesel contains no sulfur and performs as well as petroleum diesel, while reducing emissions of PM, CO, hydrocarbons, and $\mathrm{SO}_{\mathrm{x}}$. 
Microalgae are currently being pursued as the superior raw material for biodiesel production, more and more researches have been reported for all stages of microalgae biodiesel process chain. Biofuel derived from microalgae is encouraged by policy measures and its production is growing all over the world. However, biofuels cannot compete economically in market due to its higher expense in comparison with fossil fuels. One promising way to make algal biofuel production more cost-effective is to couple environmental pollution control, including biological fixation of $\mathrm{GHG}\left(\mathrm{CO}_{2}\right.$ and $\mathrm{NO}_{\mathrm{x}}$ ) and wastewater treatment. The objective of this review is to give an overview of the current status of microalgae use for biodiesel production, covering upstream (strain selection, cultivation, biomass harvesting, and drying) to downstream processes (lipids extraction, biodiesel conversion techniques). Then, several environmental benefits (e.g., $\mathrm{CO}_{2}$ sequestration, $\mathrm{NO}_{\mathrm{x}}$, and wastewater treatment) from microalgae and its combination with biodiesel production are presented. It is expected to provide a useful reference for revealing the potential and prospect of microalgae biofuel industry, and propelling the cost-effective and sustainable microalgae biodiesel industrialization.

\section{THE OVERALL MICROALGAE BIODIESEL PROCESS CHAIN OPERATION}

Recent investigations have indicated that microalgae biodiesel could be used as alternative fuel in conventional diesel engine; by this way, exhaust emission values can be improved. Tuccar and Aydin (2013) identify availability of microalgae biodiesel in diesel engines. Based on observation for fuel properties of pure microalgae biodiesel and its blends with diesel fuel, microalgae biodiesel satisfies European Biodiesel Standards (EN 14214) except its low cetane number. However, its low cetane number can be compensated by mixing microalgae biodiesel with diesel fuel. There are also decreases in $\mathrm{CO}$ and $\mathrm{NO}_{\mathrm{x}}$ emission when using microalgae biodiesel. Microalgal biodiesel production mainly comprises six steps including strain selection, cultivation, biomass harvesting, drying, lipids extraction, and transesterification. Recently, renewable fuels can be produced through the refining of a liquid biocrude produced through the thermochemical conversion of biomass, either through hydrothermal liquefaction (HTL) or pyrolysis (Neveux et al., 2014; Xu et al., 2014).

\section{STRAIN SELECTION}

Microalgae are prokaryotic or eukaryotic photosynthetic microorganisms that are incredibly diverse in natural environment (typically in freshwater and marine systems). It has been estimated that about 200,000-800,000 algal species exist, of which only about 35,000 species have been described (Ebenezer et al., 2012). Note that microalgae strain selected, as the first and important step of algae-based biodiesel industry (Scott et al., 2010), determine the corresponding nutrients and cultivation unit available for their growth. During the past decades, lots of research effort have been focused on extensive collections of microalgae strains optimal for biodiesel production.

Microalgae used as biodiesel feedstock should ideally show, as mainly selective criteria, high biomass productivities and efficient biosynthesis of lipids. Fast growth promotes high biomass productivity, which consequently increases yield per harvest volume in a certain period (productivity) and decreases cost (El-Sheekh et al., 2013). The lipid content varies among strains. Since biodiesel is produced by the transesterification of lipids (mainly triglycerides) with methanol (or other alcohol), high lipid content is one of the desirable features for using microalgae as biodiesel feedstock ( $\mathrm{Xu}$ and $\mathrm{Hu}, 2013)$. High specific growth rate depends on cell proliferation and it does not reflect the microalgae specific capacity for producing and storing lipids (Nascimento et al., 2013). Generally, high oil-producing microalgae species often couple with reduced growth rate. For instance, Chlamydomonas sp. showed the lower special growth rate $(\mu=0.3)$ than Chlamydocapsa bacillus $(\mu=0.75)$, but the lipid content was higher (15.07 versus 13.52) (Nascimento et al., 2013). Species selection should be made according to the desired products. Lipid productivity, that is the mass of oil produced per unit volume of the microalgal culture per day, depends on the algal growth rate and the oil content of the biomass (Chisti, 2007). Thus, volumetric lipid productivity of the microalga, not the single parameter (lipid content or growth rate), can be the mainly selective criterion for biodiesel production. Biomass productivities, lipids content, and productivities of some reported representatives, freshwater and marine microalgae species for biodiesel production, were summarized in Table 1. For example, some potential microalgae reported for biodiesel production were Chlorella, Scenedesmus, and Botryococcus braunii, which possesses oil levels between 20 and 50\%, along with favorable productivities (as shown in Table 1) (Bogen et al., 2013; Nascimento et al., 2013; Wang et al., 2013) and Chlorella appears in particular to be a good option for biodiesel production (Mata et al., 2010). Additionally, the marine microalgae (e.g., Dunaliella and Nannochloropsis) are more prone to mass product, a high salinity prevents extensive contamination, while allowing sea water to be directly used instead of depleting fresh water resources.

Furthermore, one of the important characteristics of microalgae strains for biodiesel production is the fatty acids' profiles of

Table 1 | Biomass productivities, lipids content, and productivities of different microalgae strains (Mata et al., 2010; Bogen et al., 2013; Nascimento et al., 2013; Wang et al., 2013).

\begin{tabular}{lccc}
\hline Microalgae species & $\begin{array}{l}\text { Biomass } \\
\text { productivity } \\
\text { (g/L/day) }\end{array}$ & $\begin{array}{l}\text { Lipid content } \\
\text { (\% dry weight } \\
\text { biomass) }\end{array}$ & $\begin{array}{l}\text { Lipid } \\
\text { productivity } \\
\text { (mg/L/day) }\end{array}$ \\
\hline Ankistrodesmus falcatus & 0.34 & 16.49 & 56.07 \\
Ankistrodesmus fusiformis & 0.24 & 20.66 & 49.58 \\
Botryococcus braunii & 0.25 & 44.97 & 112.43 \\
Botryococcus terribilis & 0.20 & 49.00 & 98.00 \\
Chlamydomonas reinhardtii & 0.24 & 22.10 & 36.17 \\
Chlamydomonas sp. & 0.24 & 15.07 & 204.91 \\
Chlorella vulgaris & 0.73 & 28.07 & \\
Dunaliella tertiolecta & $\mathbf{0 . 0 9 8 - 0 . 1 2}$ & $\mathbf{1 6 . 7 - 7 1 . 0}$ & \\
Monoraphidium contortum & 0.307 & 22.20 & $\mathbf{3 7 . 6 - 9 0 . 0}$ \\
Nannochloropsis sp. & $\mathbf{0 . 1 7 - 1 . 4 3}$ & $\mathbf{1 2 . 0 - 5 3 . 0}$ & 26.77 \\
Scenedesmus obliquus & 0.16 & 16.73 & \\
Tribonema minus & 0.170 & 50.23 & \\
& & &
\end{tabular}

Marine microalgae strains are indicated by bold text. 
the microalgae cell. The total lipids composition of microalgal biomass is composed of a large variety of chemical fractions, ranging from triacylglycerols (TAGs) to sterols (Pruvost et al., 2009), not all of which are equally well suitable for biodiesel production (Bogen et al., 2013). Lipids containing TAGs and fatty acids (saturated and monounsaturated fatty acids or their derivatives) are preferred compounds because they can be easily converted into biodiesel via transesterification (Chisti, 2007). Special attention should be taken to the polyunsaturated fatty acids with four or more double bonds (C20:4, C20:5), which are susceptible to oxidation during storage and this reduces the acceptability as biodiesel (Wang et al., 2013). Free fatty acids (FFAs) can be used as a feedstock for biodiesel production using an acidic catalytic system. The fatty acids' compositions of oleaginous microalgae (range from C14:0 to C20:0) were summarized in Table 2. The fatty acids' compositions of microalgae species most reported as promising biodiesel feedstock are composed by high proportion of palmitic acid (16:0), palmitoleic acid (16:1), stearic acid (18:0), and oleic acid (18:1) (as shown in Table 2) (Bogen et al., 2013; Nascimento et al., 2013; Wang et al., 2013). In addition, many reports described that both lipids content and fatty acids profile are affected by cultivation conditions and vary during different growth phases. Especially, nitrogen deficiency and salt stress could stimulate the accumulation of neutral lipids in Chlorella due to the modification of the metabolic pathways related to lipids accumulation (Zhang et al., 2013; Chen et al., 2014). Neutral lipids production was strongly induced in Monoraphidium contortum by nitrogen deficient conditions, and the fatty acids profile shifted towards a pronounced increase of C18:1 and C16:0 fatty acids (Bogen et al., 2013). The TAGs content of the neutral lipids fraction of Nannochloropsis sp. F\&M-M24 was increased from below 5\% under nutrient sufficiency to about 95\% under nitrogen starvation (Biondi et al., 2013).

Besides the above three factors, the ideal algal strains for biofuel production should also have characteristics as follows: (1) easy to biomass harvest and further process, (2) weak response to environmental disturbances such as temperature, and (3) accessible to metabolic engineering strategies (Chisti, 2007; Bogen et al., 2013). When the wild species available in formal collections are not feasible for commercial production of biodisesel, the application of genetic methods in microalgae to develop organisms optimized for high productivity and energy value can be taken into account. However, the progress in the genetic engineering of algae was extremely slow until recently. Currently, methods successfully used for transformation have been fulfilled for the diatom Phaeodactylum, the green alga Chlamydomonas, and the cyanobacteria Synechococcus and Synechocystis (Pulz and Gross, 2004). All of these makes it impossible to develop a number of transgenic algal strains toward the synthesis of preferred products (Singh et al., 2012). Moreover, these promising advances should be viewed with caution because transgenic algae potentially pose a considerable threat to the ecosystem and thus will most likely be banned from outdoor cultivation systems and otherwise be under strict regulation (Pulz and Gross, 2004).

\section{CULTIVATION}

\section{Cultivation conditions}

In general, there are four major types of cultivation conditions for microalgae: photoautotrophic, heterotrophic, mixotrophic, and photoheterotrophic (Chojnacka, 2004). Under photoautotrophic cultivation, microalgal cells can trap light energy as the energy source and assimilate $\mathrm{CO}_{2}$ as the carbon source (Yang et al., 2000). Heterotrophic utilize organic compounds (e.g., glucose, acetate, glycerol) as both energy and carbon source in total darkness, whereas light is required to use organic compounds as carbon source for photoheterotrophic process. Mixotrophy is broadly defined as a growth regime in which $\mathrm{CO}_{2}$ and organic carbon are simultaneously assimilated, both respiratory and photosynthetic metabolism operating concurrently (Lee, 2007). It was reported that only photoautotrophic cultivation is technically and economically feasible to culture microalgae in commercial scale, typically at outdoor environment where sunlight is abundant and free (Lam and Lee, 2012). Carbon constitutes half of the weight of the biomass, it is necessary to supply large amounts of carbon in the form of carbon dioxide due to its low price. Moreover, photoautotrophic microalgae are able to capture $\mathrm{CO}_{2}$ from flue gases, an added advantage to the culture system. However, photoautotrophic method has its limitation especially in countries where

Table 2 | Fatty acid profiles (\% of total fatty acids) of different microalgae strains under regular phototrophic growth conditions (Bogen et al., 2013; Nascimento et al., 2013; Wang et al., 2013).

\begin{tabular}{|c|c|c|c|c|c|c|c|c|c|c|c|}
\hline \multirow[t]{2}{*}{ Microalgae strains } & \multicolumn{11}{|c|}{ Fatty acid composition ( $\%$ of total fatty acids) } \\
\hline & C14:0 & C15:0 & C16:0 & C16:1 & C16:2 & C17:0 & C18:0 & C18:1 & C18:2 & C18:3 & C20:0 \\
\hline Ankistrodesmus falcatus & 1.07 & & 30.23 & 0.47 & & 0.48 & 2.72 & 24.79 & 2.00 & 26.86 & \\
\hline Ankistrodesmus fusiformis & 2.02 & & 26.95 & 0.25 & & 0.20 & 2.10 & 19.61 & 12.23 & 26.50 & \\
\hline Botryococcus braunii & 0.73 & & 7.17 & & & & 1.59 & 77.88 & 5.16 & 5.34 & \\
\hline Botryococcus terribilis & & & 35.22 & & & & 3.12 & 39.74 & 5.02 & 7.22 & \\
\hline Chlamydomonas reinhardtii & & & 14.30 & 4.10 & 11.40 & & 2.40 & 26.30 & 17.60 & 10.40 & \\
\hline Chlamydomonas sp. & 1.61 & & 50.77 & 0.28 & & 1.81 & 11.54 & 13.77 & 3.93 & 2.76 & \\
\hline Chlorella vulgaris & 0.63 & & 40.31 & 3.16 & & 0.51 & 8.01 & 29.89 & 8.54 & 1.57 & \\
\hline Monoraphidium contortum & & & 24.30 & 3.40 & 3.20 & & 3.80 & 38.50 & 8.00 & 5.00 & 1.50 \\
\hline Scenedesmus obliquus & 1.06 & & 52.07 & & & & 7.48 & 21.46 & 4.60 & 2.83 & \\
\hline Tribonema minus & 6.85 & 0.56 & 28.35 & 50.65 & 1.55 & & 1.02 & 2.96 & 0.71 & & \\
\hline
\end{tabular}


sunlight intensity is not always suitable for photoautotrophic culture available throughout the year. The introduction of sufficient natural or artificial light to allow massive growth and dense populations is the main objective and a limiting factor of the cultivation (Perez-Garcia et al., 2011)

Alternatively, heterotrophic cultivation provides an immediate solution to this problem as some of the microalgae strains can grow under dark environment. Relatively high lipids yield and biomass productivity can be attained through heterotrophic cultivation mode. Heterotrophically cultivated Chlorella protothecoides has been shown to accumulate as much as $55 \%$ of its dry weight as oil, compared to only $14 \%$ in cells grown photoautotrophically (Miao and Wu, 2006b). This phenomenon indicates that heterotrophic culture provides an absolutely good opportunity for large-scale production by using conventional fermentation bioreactor. Nevertheless, this mode of cultivation possesses a number of drawbacks that need to be resolved: (1) the limited number of available heterotrophic algal species, (2) potential contamination by bacteria, (3) inhibition of growth by soluble organic substrates at low concentrations, and (4) the inability to produce some lightinduced products, such as pigments (Chen, 1996). The former three problems can be resolved by screening microalgae strains, which have strong pollution tolerance and are able to grow in heterotrophic condition and adapt to a wide range of organic carbon. The limited light-induced products can be overcome through the following two ways: (1) Mixotrophic cultivation. For mixotrophic culture, microalgae are live either photoautotrophic or heterotrophic pathway depending on the concentration of organic compounds and light intensity available. Heterotrophic metabolism can obtain higher biomass but light-induced products are very low, whereas adequate lighting is conducive to the synthesis of light-induced product. Therefore, the artificial control of photoautotrophic and heterotrophic ratio (Ogbonna et al., 2002), such as modulating light intensity, increasing $\mathrm{CO}_{2}$ supply, and reducing the addition rate of organic carbon to obtain higher biomass and light-induced products. (2) The two-step culture methods, namely, the first heterotrophic or mixotrophic cultivation is to obtain higher biomass, and then transferred to autotrophic conditions, where light induced to produce required metabolite products.

\section{Bioreactors}

Open systems (e.g., raceway ponds) and closed photobioreactors (PBRs) are two major types of microalgae culture systems. The shallow raceway pond, in which the suspension is mixed with a paddle wheel, is the most widely used among the prevailing microalgae culturing devices, because it is relatively easy and cheap to construct and operate (Chaumont, 1993; Doucha and Lívanský, 2006). Currently, over $90 \%$ of world microalgae biomass production is realized in large raceway ponds. However, the low biomass productivity at field level is its fatal drawback considering the competition of land for traditional crops when commercial developments of microalgae biofuel are promoted (Chen et al., 2013). They are strongly limited by contamination (by other algae, bacteria), the degree of which depends on climatic conditions (for example, it is very difficult to maintain an open algal culture in the tropics during the rainy season).
Because of the aforementioned drawbacks of open cultures, there are many different PBR designs, which are proposed for biofuel production. To develop an efficient PBR, it is necessary to consider various factors such as suitable construction materials, hydrodynamics, efficient mixing, mass and light transfer, heating/cooling, $\mathrm{CO}_{2}$ supply and oxygen removal, etc. These factors also highly correlate to each other for the productivity of PBR (Yoo et al., 2013). For example, the tubular PBRs possess two regions, light-illuminated surface and dark region inside of reactor. For efficient light transfer to microalgal cells, mixing is required to circulate cells between dark and bright region of PBR in addition to optimization of light path length and shape of PBR. Note that, apply this PBRs system to indoor and outdoor conditions for longterm cultivation and evaluate its performance. PBRs appear in different common configuration: tubular reactors, flat plate reactors, and column reactors (bubble or airlift columns). The main advantages and limitation of open ponds and PBRs are summarized in Table 3 (Singh et al., 2011b; Pires et al., 2012; Arbib et al., 2013). Compared to open ponds, PBRs have several advantages (Moazami et al., 2012; Arbib et al., 2013): (1) PBRs are closed to the atmosphere and protect the cultivated alga to some extent (note that by being closed, PBR are less prone, but not immune, to contamination); (2) growth parameters (e.g., temperature) can be better controlled; (3) due to a higher surface-to-volume (S/V) ratio, PBRs allow to reach higher volumetric productivities and cell concentrations; (4) closed systems eliminate or strongly reduce evaporation; (5) since PBRs have not been engineered to the extent of other bioreactors in commercial use, there are rooms for improvement. Although many different PBR designs have been proposed for biofuel production, few of them have been tested at pilot scale, none developed at the (large) scale necessary for a complete and correct evaluation because of high cost and reduced scalability. Thus, the main issues that impact on the reactor's performance (i.e., suitable construction materials, efficient mixing, heating/cooling, $\mathrm{CO}_{2}$ supply and oxygen removal), although explored at pilot level, still await evaluation at real scale (Borowitzka and Moheimani, 2013). There is a dichotomy, need to be solved in future, between PBRs and open systems as the possible culture solution to be employed in large-scale microalgae biomass production.

\section{BIOMASS HARVESTING}

After cultivation, the microalgae biomass have to be separated from its growth medium and recovered for downstream processing. However, the algae grow in dilute suspension $\left(<0.5 \mathrm{~kg} / \mathrm{m}^{3}\right.$ dry biomass) and the negative surface charge results in dispersed stable algal suspensions (Sanyano et al., 2013). Most of the oleaginous microalgae species are small-size single-cell microorganism (cell dimension $<30 \mu \mathrm{m}$ ) such as Scenedesmus sp. and Chlorella sp. (Phukan et al., 2011; Wang et al., 2013). Microalgae harvesting remain a major hurdle to industrial scale processing, and it was estimated to account for $20-30 \%$ of the total biomass production cost (Molina Grima et al., 2003). Thus, microalgae harvesting is still an active area for research, being possible to develop an appropriate and economical harvesting system.

When considering commercial-scale processes for dewatering and recovering algal biomass for further downstream processes, a traditional harvesting method may involve up to two steps: 
Table 3 |Advantages and limitations of open ponds and PBRs (Singh et al., 2011c; Pires et al., 2012; Arbib et al., 2013).

\begin{tabular}{|c|c|c|}
\hline Production system & Advantages & Limitations \\
\hline \multirow[t]{6}{*}{ Raceway pond } & Easy to construct & High evaporative losses \\
\hline & Relatively cheap & High diffusion of $\mathrm{CO}_{2}$ to the atmosphere \\
\hline & & Poor light utilization \\
\hline & Easy maintenance & Requirement of large areas of land \\
\hline & Good for mass cultivation & Microbial and native algae contamination \\
\hline & & Poor biomass productivity \\
\hline \multirow[t]{3}{*}{ Tubular photobioreactor } & Relatively high biomass productivities & High initial investment costs \\
\hline & Suitable for outdoor mass culture & Toxic accumulation of $\mathrm{O}_{2}$ fouling overheating \\
\hline & Less prone to contamination & \\
\hline \multirow[t]{6}{*}{ Flat plate photobioreacor } & Relatively high biomass productivities & Scale-up require many support materials and large \\
\hline & Large illumination surface area & areas of land \\
\hline & Smaller light path & \\
\hline & Less prone to contamination & Difficult temperature control \\
\hline & Lower power consumption & \\
\hline & Small accumulation of dissolved oxygen & \\
\hline Column photobioreactor (airlift and & High mass transfer capacity & \\
\hline \multirow[t]{5}{*}{ bubble column bioreactor) } & Easy to sterilize & Small illumination surface area \\
\hline & Low fouling & High energy usage \\
\hline & & Construction require sophisticated \\
\hline & Reduced photoinhibition/photo-oxidation & Materials \\
\hline & Good mixing with low shear stress & Decrease of illumination surface area upon scale-up \\
\hline
\end{tabular}

(1) bulk harvesting (known as primary harvesting) - to separate microalgae from suspension, such as sedimentation, flocculation, and flotation; (2) thickening (known as secondary dewatering) to concentrate the microalgae slurry after bulk harvesting, such as centrifugation and filtration (Grima et al., 2003; Lam and Lee, 2012; Sharma et al., 2013). An optimal harvesting technique should be independent of the cultured species, consume little energy and few chemicals and not damage the valuable products in the extraction process. Here, we summarize the advantages and disadvantages of conventional techniques (Table 4) (Chen et al., 2011a; Salim et al., 2011; Milledge and Heaven, 2013; Ahmad et al., 2014a). The centrifugation process, whereby solid-liquid separation is driving by a much greater force (gravity) to promote accelerated settling of microalgae cells, can be used for almost all types of microalgae reliably and without difficulty (Pires et al., 2012). However, centrifugal recovery is only feasible if the targeted metabolite is a high-value product because the process is highly energy intensive. In addition, using this technique at a large scale is problematic because of high power consumption, which increases production costs.

Filtration is a physical separation process by filter (membrane), which is characterized by their efficiency, reliability, and safety for the solid-liquid separation. Membrane filtration removes completely debris and microalgae cells from the culture medium, realizing water recycling. Different membrane materials [e.g., polyvinylidene fluoride (PVDF), polyvinyl chloride (PVC), polysulfone membrane (PS)] (De Baerdemaeker et al., 2013; Sun et al., 2013a) and membrane pore size [microfiltration, ultrafiltration (UF)] were tested for algae harvesting, and PVDF was the superior polymer, and UF showed better fouling resistance (De Baerdemaeker et al., 2013). However, fouling limits the widespread use of membrane separation technology due to the reduction of permeation flux during the separation process. The methods such as optimization of operating conditions, physical and chemical cleaning, new membrane development, or modification of existing membranes have applied to reduce the impact of fouling. Two types of thickening methods (without prior bulk harvesting) centrifugation and filtration - are too costly and energy intensive for large-scale biofuels production. In this regard, the bulk harvesting technologies as pre-concentration step may play an important role in reducing the energy consumption during the thickening process of microalgae slurry (Uduman et al., 2010).

Flocculation is commonly performed before secondary dewatering processes for reducing the cost of harvesting microalgae. Flocculation can be achieved by various methods and addition of chemicals known as flocculants to counter the surface charge on the algae is widely applied. The inorganic coagulants are usually in the form of aluminum and ferric salts, such as aluminum sulfate, ferric sulfate, and ferric chloride (Grima et al., 2003). Sanyano et al. (2013) reported that the optimum flocculation of marine Chlorella sp. was achieved at ferric chloride dosage $143 \mathrm{mg} / \mathrm{L}, \mathrm{pH} 8.1$, and settling time $40 \mathrm{~min}$. Harvesting efficiency of Nannochloris oculata was $96 \%$ when using $0.0016 \mathrm{ng}$ of $\mathrm{AlCl}_{3} /$ cell at pH 5.3 (GarzonSanabria et al., 2012). Inorganic flocculants require acidic or alkaline $\mathrm{pH}$ for optimal microalgae flocculation. Recently, organoclay as a novel flocculant for rapid and efficient harvesting of microalgae was demonstrated. Lee et al. (2013b)synthesized cationic charged aluminum- and magnesium-backboned organoclays, 
Table 4 | Comparison of microalgal harvesting and drying methods (Ahmad et al., 2014a; Salim et al., 2011; Chen et al., 2011a; Milledge and Heaven, 2013).

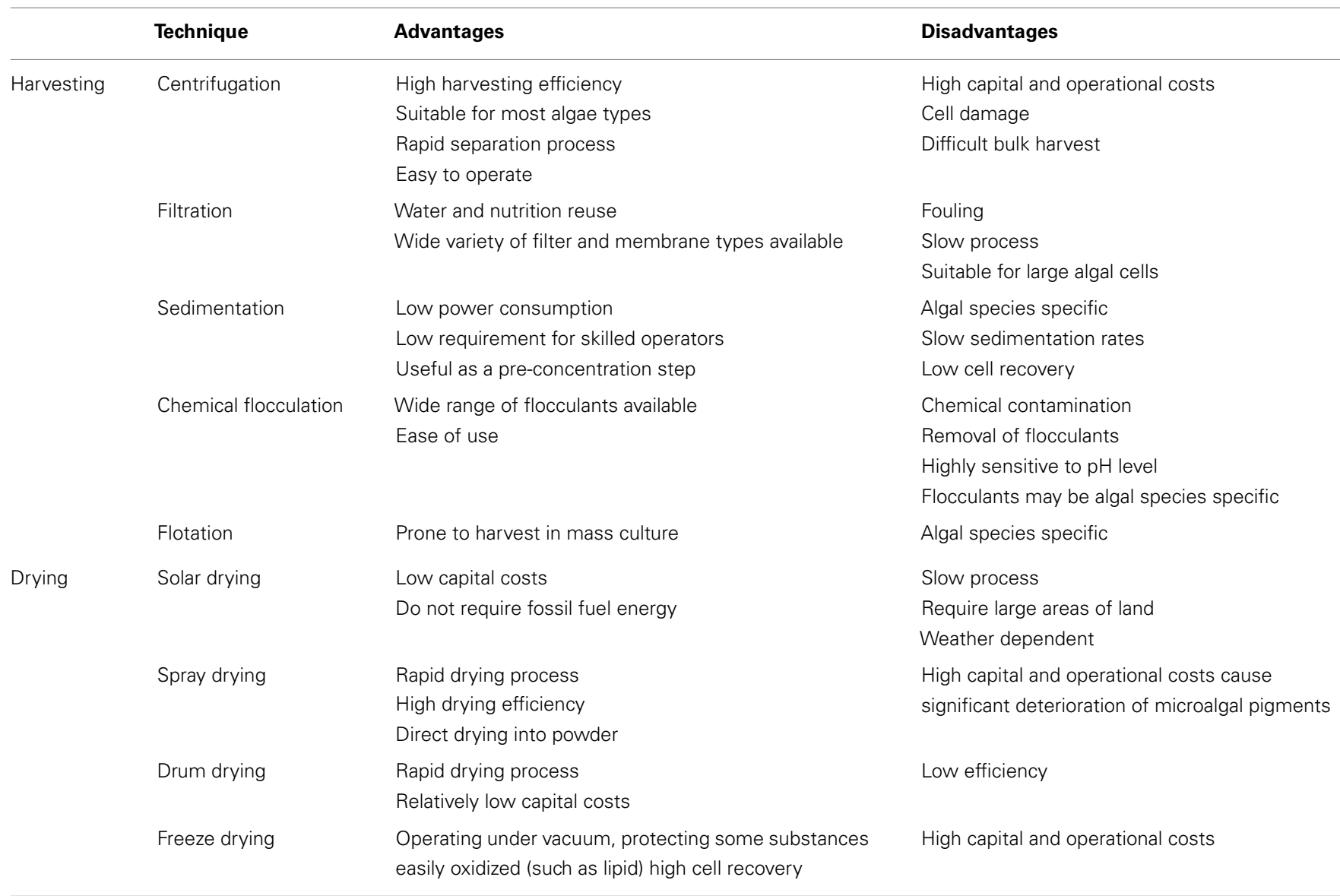

harvesting efficiencies of oleaginous Chlorella sp. are almost 100\% at concentrations above $0.6 \mathrm{~g} / \mathrm{L}$ while maintaining a neutral $\mathrm{pH}$. However, the referred inorganic multivalent metal salts are toxic and expensive when commercial-scale culture of microalgae. The non-toxic organic polymer, such as polyacrylamide copolymers, chitosan, and cationic starch (Oh et al., 2001; Vandamme et al., 2010), have been intensively investigated for large-scale applications, but they are not economical for microalgae due to its higher price. The flocculant residuals in both algal biomass and harvested water are not only negative for later processing but also disadvantages for culture medium recycling.

Some studies reported that flocculation of microalgae can occur spontaneously without the need for chemicals, referred to as autoflocculation, which can be induced by increasing the medium $\mathrm{pH}$ (Beuckels et al., 2013). Harvesting efficiency higher than $90 \%$ of Chaetoceros calcitrans was achieved by adjusting the culture $\mathrm{pH}$ to 10.2 using either $\mathrm{NaOH}$ or $\mathrm{KOH}$ (Harith et al., 2009). However, autoflocculation can only be applied for the limited strains. The electrolytic method also has the potential to separate algae without the addition of chemicals. However, the high power that needs to be input are not easy to scale-up and results in a temperature increase that may damage the system (Kim et al., 2012).

Flotation can capture particles with a diameter of less than $500 \mathrm{~lm}$ by collision between a bubble and a particle and the subsequent adhesion of the bubble and the particle (Chen et al., 2011a). Based on bubble sizes used in the flotation process, the applications can be divided into dissolved air flotation (DAF), dispersed flotation, and electrolytic flotation. The flotation process where microalgae float to the surface of medium is prone to harvest in microalgae mass culture, and has been used for specific strains. The flotation activity of Spirulina platensis without flocculant showed a maximum value of $80 \%$ after $3 \mathrm{~h}$ of settling (Kim et al., 2005). Microalgae stain Tribonema minus, which were cultivated for 21 days in 40 -L glass panel, were harvested by DAF without any flocculants in laboratory, the recovery efficiency reach up to $95.57 \%$ (Wang et al., 2013).

\section{DRYING}

The percentage of water contained in algal paste after secondary dewatering should not exceed $50 \%$ before oil extraction (Kumar et al., 2010), and extensive drying of microalgae biomass is required for biofuels production as the presence of water interferes with the extraction and/or conversion of algal lipids to biodiesel. There are some common methods for drying microalgae after secondary dewatering: spray drying, drum drying, freeze drying, and solar drying (Richmond, 2008). Solar drying is considered the best and economical method to dry wet microalgae paste. However, solar drying is not feasible in temperate countries where 
sunlight at certain time of the year is limited (Sharma et al., 2013). And it requires large land areas for large-scale operations. The other drying methods are not economical and lead to a negative energy balance in producing microalgae biodiesel because of heavy dependency on fossil fuels. The advantages and disadvantages of conventional techniques in drying were summarized in Table 4. Thus, it is urgently needed to develop new technologies or approaches to ensure the sustainability of microalgae biofuel industry.

\section{LIPIDS EXTRACTION}

For biodiesel production, lipids and fatty acids have to be extracted from the microalgae biomass. Lipids' extraction efficiency is directly related to the overall process efficiency in biodiesel production. Therefore, extraction process is very important before transesterification of lipids takes place. It is necessary to develop efficient and cheaper extraction processes to reach industrial biodiesel production at appropriate costs. The extraction of microalgae lipids is usually performed using chemical solvent such as hexane Soxhlet extraction (Soxhlet, 1879) and mixed methanolchloroform (2:1 v/v) (Bligh-Dyer method) (Bligh and Dyer, 1959). Hexane Soxhlet extraction is generally used to capture high-quality lipids such as triglycerides and fatty acids, which are easily esterified into biodiesel (Demirbas, 2008; Kanda et al., 2013). The Bligh-Dyer method is useful for extracting oily substances because a wide range of oily components can be isolated from microalgae. These two processes are effective to extract microalgae lipids, but the extraction efficiency is highly dependent on microalgae strains. Chemical solvent has high selectivity and solubility toward lipids and therefore, even inter-lipids can be extracted out through diffusion across microalgae cell wall. Nevertheless, the disadvantages of using chemical solvent are mostly related to their high toxicity toward human and surrounding environment. In addition, it is not sustainable to use $n$-hexane and chloroform since both solvents are conventionally derived from non-renewable fossil fuels.

One alternative to the use of organic solvent is to carry out extractions using the subcritical or supercritical lipids. Subcritical extraction used elevated pressures to keep the solvent as liquid state when the temperature reached above the boiling point, which greatly improved extraction efficiency. Considering ethanol is relatively cheap and safety than hexane and easy recycling, subcritical ethanol extraction was performed in total lipids extraction from microalgae paste. Chen et al. (2011b) applied subcritical ethanol extract lipids from wet microalgae paste of Nannochloropsis sp., the optimum extraction conditions were $10 \%$ moisture, $40: 1$ ratio (the solvent to microalgae phase ratio), $135^{\circ} \mathrm{C}, 1.5 \mathrm{MPa}$, and $50 \mathrm{~min}$, which could produce $90.21 \%$ recovery rate of the total lipids. The recovery rate of the total lipid of T. minus was $72.82 \%$ when the solvent ethanol $(95 \%, \mathrm{v} / \mathrm{v})$ to microalgae (dry weight) ratio (v/w) was $20: 1$ at $105^{\circ} \mathrm{C}$ for $100 \mathrm{~min}$ (Wang et al., 2013). By using subcritical ethanol extraction, the drying process is not needed, which thus could avoid the energy cost. Note that the effects of various operational parameters including moisture content, solvent (volume) to microalgae (dry weight) ratio, extraction temperature, pressure, and time will be needed to investigate to improve extraction performance of total lipids. Several supercritical fluids mainly supercritical- $\mathrm{CO}_{2}$ have received the most interest and applied to microalgae lipids extraction for biodiesel production recently (Mendes et al., 1994; Andrich et al., 2006; Gouveia et al., 2007; Tang et al., 2011; Mouahid et al., 2013). Supercritical- $\mathrm{CO}_{2}$ extraction is non-toxic and provide non-oxidizing environment to avoid degradation of extracts. Moreover, no separation step is needed since $\mathrm{CO}_{2}$ is gaseous at ambient pressure (Mouahid et al., 2013). However, high cost of supercritical- $\mathrm{CO}_{2}$ extraction prevents its development. Hence, a complete analysis is urgently required to compare the feasibility of supercritical lipids and chemical solvent extraction in industrial scale, typically in terms of energy efficiency and cost-effectiveness.

\section{TRANSESTERIFICATION}

The most accessible technology reported for biodiesel production currently is transesterification reaction in which triglycerides (lipids compounds) are reacted with short chain alcohol (e.g., methanol or ethanol) in the presence of catalyst and the final reaction products are known as biodiesel [fatty acid methyl esters (FAMEs)] and glycerol (by-product) (Lam et al., 2010). The most commonly used catalysts for microalgae lipids transesterification are discussed in the next subsections.

\section{Homogeneous alkaline and acid catalysts}

Homogeneous alkaline catalysts (e.g., $\mathrm{KOH}$ and $\mathrm{NaOH}$ ) have been the most commonly used route for biodiesel production as it catalyzes the reaction at low temperature and atmospheric pressure. In addition, high conversion yield can be achieved in short time (minutes), being the most economical way to catalyze the transesterification reaction (Meher et al., 2006; Sharif Hossain et al., 2008). However, formation of soaps in the presence of the FFAs $(>1 \%)$ and water $(>0.06 \%)$ will lead to lower biodiesel yield and increase the difficulty to separate biodiesel from co-product (Hidalgo et al., 2013). Therefore, acid catalysts have been proposed to overcome the limitations of high FFAs content as the catalysts are not sensitive toward FFAs level in oil. The commonly used acid catalysts in the transesterification process are $\mathrm{H}_{2} \mathrm{SO}_{4}$ and $\mathrm{HCl}$. Besides, the acid catalysts can promote esterification (FFAs are converted to alkyl ester) and transesterification simultaneously. Velasquez-Orta et al. (2013) reported that lipids conversion of Chlorella sp. was obtained using sulfuric acid as catalyst, and a FAME yield of $92 \pm 2 \%$ was obtained at a catalyst:lipids molar ratio of 0.35:1.

Based on currently available technologies, combination of both acid and base catalysts (two-step reaction) has been proposed to produce biodiesel from lipids with a high FFAs content (Canakci, 2007; Francisco et al., 2010). Microalgae lipids is initially subjected to acid pre-treatment so that its FFAs level is reduced to less than $1 \%$ weight, followed by the second transesterification step performed by using an alkaline catalyst. In a study, biodiesel production from T. minus oil was followed by two-step catalytic conversion, the conversion rate of TAGs reached $96.52 \%$ and the biodiesel product from T. minus conformed to Chinese National Standards (Wang et al., 2013). Nevertheless, high concentrations of the base catalysts are necessary to neutralize the acid catalysts from the first transesterification step, increasing the operational costs. 


\section{Heterogeneous catalysts}

Heterogeneous catalysis (e.g., $\mathrm{CaO}, \mathrm{MgO}$, mixed $\mathrm{CaO}-\mathrm{Al}_{2} \mathrm{O}_{3}$, etc.) has also been developed for biodiesel production. Heterogeneous solid catalysts have several advantages as it is non-corrosive and can be recycled. Furthermore, the catalysts offer facile product separation through filtration and therefore minimize product contamination and number of water washing cycle. However, the use of heterogeneous catalysts can result in low biodiesel conversion yields in comparison with homogeneous catalysts, which may be due to the fact that homogeneous catalysts can dissolve in the bulk liquid while heterogeneous catalysts do not dissolve in the bulk liquid producing mass transfer limitations (Liu et al., 2007; Lam et al., 2010)

\section{Lipases}

Recently, enzymatic transesterification using lipases has become more attractive for biodiesel production, as it allows the use of mild reaction conditions, avoids the generation of wastewater, and eases the recovery of high purity glycerol, which could solve downstream processing problems. Lipases can be used to transform lipids with high FFAs amount, consequently the catalytic effectiveness is not affected by FFAs and water in the reactors, which is a limitation for homogeneous alkaline catalysis. However, the high cost of enzyme remains a barrier for its industrial applications. In order to decrease the cost of the process, the enzyme could be immobilized in a suitable carrier and reused. Lipases do not require excessive energy expenditures, and it facilitates its recovery and reuse if the catalyst is immobilized (Arias-Penaranda et al., 2013). In relation to microalgae biodiesel production, there are only a few reports related to transesterification with lipases. The immobilized Novozym 435 has been investigated widely and is reported to exhibit the best performance among different lipases sources (Hernandez-Martin and Otero, 2008; Talukder et al., 2009). Moreover, converting Scenedesmus incrassatulus lipids to FAMEs by Novozym 435 has come true and a higher FAMEs yield can be obtained in a shorter reaction time (Arias-Penaranda et al., 2013).

\section{In situ transesterification}

Traditional process to produce biodiesel mainly consists of two separate steps: lipids extraction followed by transesterification. An alternative to the conventional process is the in situ transesterification (or direct transesterification) in which the lipids extraction and transesterification carried out in one step was extensively exploration. Thus, in situ transesterification, which is directly contacted with chemical solvent in the presence of catalysts to biodiesel, shows promise of both simplifying and reducing the cost of producing biodiesel from microalgae biomass (Lam and Lee, 2012). Chemical solvent plays two significant roles in this process: (1) as a solvent to extract lipids out from microalgae biomass and (2) as a reactant in transesterification reaction. Table 5 shows a summary of different studies on direct transesterification for biodiesel production from microalgae biomass.

According to the recent report (Sathish et al., 2014), the presence of moisture at greater than $20 \%$ by mass in algal biomass significantly decreased biodiesel recovery when using in situ transesterification. Consequently, the algal biomass need to be dried prior to the in situ transesterification procedure due to the inhibitory nature of water on the reaction. Three explanations have been commonly presented to describe this inhibitory effect (Sathish et al., 2014): (1) the formation of FAMEs is a reversible reaction, therefore, water can hydrolyze biodiesel back to methanol and FFAs, (2) water contained within the biomass can shield lipids from the extracting solvent, preventing lipids from being brought into the reaction, and (3) the acid catalysts can be deactivated due to water competing for available protons in the reaction. In recent years, the in situ transesterification process was developed to directly convert wet oil-bearing microalgae biomass into biodiesel. Dang-Thuan et al. (2013) reported that Chlorella vulgaris ESP-31 biomass (water content of $86-91 \%$, oil content of $14-63 \%$ ) was pretreated by sonication to disrupt the cell walls and then directly mixed with methanol and solvent to carry out the enzymatic transesterification and achieve over $90 \%$ biodiesel conversion.

\section{OTHER APPLICATIONS AND BY-PRODUCTS FROM MICROALGAE ENVIRONMENTAL APPLICATIONS $\mathrm{CO}_{2}$ biofixation from flue gases by microalgae cultivation}

Addressing global warming concern is one of the key global challenges and $\mathrm{CO}_{2}$ acts as a principal GHG effect to contribute the global warming. About $75 \%$ of the total anthropogenic $\mathrm{CO}_{2}$ emissions were derived from fossil fuel burning (Nakanishi et al., 2014). To date, several technologies used to capture $\mathrm{CO}_{2}$ are physical and chemical absorption, cryogenic distillation, and membranes separation (Abu-Khader, 2006). The capture $\mathrm{CO}_{2}$ is then transported and stored in geological formations. However, these procedures should only be considered as short-term solutions because they are energy consuming and the capture $\mathrm{CO}_{2}$ need to be disposed of. Additionally, the $\mathrm{CO}_{2}$ biofixation by microalgae has drawn much attention as an environmentally friendly $\mathrm{CO}_{2}$ mitigation strategy. Carbon is a key resource for successful microalgae production as it is the main element of microalgae (36-65\% of the dry matter). The diffusion of $\mathrm{CO}_{2}$ from the atmosphere into microalgae culture is insufficient to support the rapid growth of microalgae (growth velocity less than 5\% of its potential capacity) (Benemann, 1993). Therefore, microalgae culture by using the flue gases can reduce GHG emissions, while addressing the microalgae culture carbon supply and leading the production of biomass energy through photosynthesis.

Besides $\mathrm{CO}_{2}$, flue gases contain many different compounds such as $\mathrm{H}_{2} \mathrm{O}, \mathrm{O}_{2}, \mathrm{~N}_{2}$, nitrogen oxides $\left(\mathrm{NO}_{\mathrm{x}}\right)$, sulfur oxides $\left(\mathrm{SO}_{\mathrm{x}}\right)$, unburned carbohydrates ( $\mathrm{CxHy}$ ), $\mathrm{CO}$, heavy metals, halogen acids, and PM. Several chemical compounds ( $\mathrm{SO}_{\mathrm{x}}$, heavy metals, etc.) have shown to be toxic to some microalgae (Lee et al., 2000), but well tolerated by others. Yang et al. (2004) reported low concentrations of bisulfite $(0-1 \mathrm{mmol} / \mathrm{L})$ had no adverse influence on the growth of B. braunii, but bisulfite was toxic at high concentrations ( $>1 \mathrm{mmol} / \mathrm{L}$ ). However, Scenedesmus dimorphus grew well $(3.20 \mathrm{~g} / \mathrm{L})$ with simulated flue gas $\left(15 \% \mathrm{CO}_{2}, 400 \mathrm{ppm} \mathrm{SO}_{2}\right.$, 300 ppm NO, balance $\mathrm{N}_{2}$ ) (Jiang et al., 2013). To better engineer flue gas-fed microalgal cultures, the effects of all flue gas compounds, tolerance of various microalgae to flue gas compounds, and the interaction of flue gas compounds and microalgae need to be assessed (de-Bashan and Bashan, 2010; Van den Hende et al., 2012). 
Table 5 | Comparison of different catalysts for direct transesterification of microalgae biomass.

\begin{tabular}{|c|c|c|c|c|c|c|c|}
\hline & \multirow[t]{2}{*}{ Catalysts } & \multicolumn{3}{|c|}{ Reaction conditions } & \multirow[t]{2}{*}{ Microalgae } & \multirow{2}{*}{$\begin{array}{l}\text { Alkyl } \\
\text { esters (\%) }\end{array}$} & \multirow[t]{2}{*}{ Reference } \\
\hline & & $\begin{array}{l}\text { Alcohol:oil } \\
\text { (mol/mol) }\end{array}$ & $T\left({ }^{\circ} \mathrm{C}\right)$ & $\begin{array}{l}\text { Time } \\
\text { (h) }\end{array}$ & & & \\
\hline \multirow[t]{3}{*}{ Acid catalysts } & $\mathrm{H}_{2} \mathrm{SO}_{4}$ & $56: 1$ & 30 & 4 & Chlorella protothecoides & 80 & Miao and Wu (2006a) \\
\hline & $\mathrm{HCl}$ & $56: 1$ & - & 2 & Chlorella sp. & 74 & Ahmad et al., 2014b \\
\hline & $\mathrm{HCl}$ & $82: 1$ & 65 & 6.4 & Scenedesmus obliquus & 91 & Mandal et al. (2013) \\
\hline \multirow[t]{3}{*}{ Alkaline catalysts } & $\mathrm{KOH}$ & $12: 1$ & 65 & 0.5 & Tribonema minus & 96.5 & Wang et al. (2013) \\
\hline & $\mathrm{KOH}$ & $12: 1$ & 65 & 0.5 & Scenedesmus sp. & 91.6 & Chen et al. (2012) \\
\hline & $\mathrm{NaOH}$ & $6: 1$ & 65 & 0.85 & Chlorella protothecoides & 98.76 & Makareviciene et al. (2014) \\
\hline Heterogeneous catalysts & $\mathrm{CaO} / \mathrm{Al}_{2} \mathrm{O}_{3}$ & $30: 1$ & 50 & 4 & Nannochloropsis oculata & 97.5 & Umdu et al. (2009) \\
\hline \multirow[t]{4}{*}{ Lipases } & Novozyme 435 & $6: 1$ & 50 & 24 & Scenedesmus & 71.7 & Arias-Penaranda et al. (2013) \\
\hline & & & & & incrassatulus CLHE-Si01 & & \\
\hline & Novozyme 435 & - & 60 & 6 & Chlorella sp. KR-1 & 75.5 & Lee et al. (2013a) \\
\hline & Novozyme & $8: 1$ & 50 & 6 & Oedogonium sp. & 92 & Haq et al. (2014) \\
\hline
\end{tabular}

Utilization of $\mathrm{CO}_{2}$ by microalgae for its growth takes place by two stages: absorption of $\mathrm{CO}_{2}$ from flue gases by mass transfer and $\mathrm{CO}_{2}$ fixation by photosynthesis. Note that the ability of $\mathrm{CO}_{2}$ uptake by microalgae varies dramatically among algal species. It is necessary to select suitable algal candidates to fix $\mathrm{CO}_{2}$ from actual flue gases under a large collection of algal cultures although it is very time-consuming and technical challenging. Microalgae species reported for biological carbon fixation include Chlorella sp. (Doucha et al., 2005), Scendesmus sp. (Liu et al., 2013), and Dunaliella tertiolecta (Farrelly et al., 2014). Lam and Lee (2012) developed a pilot-scale microalgal fixation $\mathrm{CO}_{2}$ system to capture $\mathrm{CO}_{2}$ from actual flue gas and Scenedesmus obliquus was able to tolerate high concentration of $\mathrm{CO}_{2}$ up to $12 \%(\mathrm{v} / \mathrm{v})$ with optimal removal efficiency of $67 \%$. In addition, B. braunii is appropriate for cultivation with flue gas and lipid productivity reach $20.65 \mathrm{mg} / \mathrm{L} /$ day (Yoo et al., 2010). Liu et al. (2013) described a high throughput screening method to rapidly identify microalgae strains that can tolerate high $\mathrm{CO}_{2}$ condition or flue gases from a large pool of culture collection species.

$\mathrm{CO}_{2}$ mass transfer is a key factor in cultivating microalgae due to low solubility of $\mathrm{CO}_{2}$ in water. The $\mathrm{CO}_{2}$ solubility in water is generally very low, i.e., $1650 \mathrm{ppm}$ at $25^{\circ} \mathrm{C}$ in pure water. Current methods for $\mathrm{CO}_{2}$ feeding to algae cultures rely on the sparging of $\mathrm{CO}_{2}$ directly from flue gases or pure $\mathrm{CO}_{2}$. However, $\mathrm{CO}_{2}$ feeding through sparging limits the amount of $\mathrm{CO}_{2}$ that can be absorbed in the liquid leading to losses to the atmosphere (low carbon utilization efficiency) because of the poor $\mathrm{CO}_{2}$ solubility in water (Soletto et al., 2008). Also, this system requires a considerable amount of energy for effective contacting of the $\mathrm{CO}_{2}$ with the liquid phase and achieving high enough $\mathrm{CO}_{2}$ concentrations in the liquid, resulting in its limitation during scale-up (Schipper et al., 2013).

Absorption of $\mathrm{CO}_{2}$ by chemical methods based on the use of absorption liquids can be used to stabilize the $\mathrm{CO}_{2}$ as carbonate and then is fed to algae. One such method is $\mathrm{CO}_{2}$ capture in alkaline solution as absorption liquid (Iancu et al., 2012). Because the carbon is introduced into the algae culture in a soluble form, this directly improves the efficiency of $\mathrm{CO}_{2}$ uptake by the algae compared to direct injection of $\mathrm{CO}_{2}$. Absorption liquids such as potassium carbonate are cheap and also reduce the energy requirement needed for the sparging of $\mathrm{CO}_{2}$ into algae cultures (Schipper et al., 2013). However, it is necessary to select algae strains that should be able to grow under alkaline conditions. Hsueh et al. (2007) reported that the algae from alkaline hot spring could grow well over $\mathrm{pH} 11.5$ and $50^{\circ} \mathrm{C}$. They enhance the $\mathrm{CO}_{2}$ mass transfer by fivefold with a high-performance alkaline absorber such as a packed tower and regenerating the alkaline solution with algal photosynthesis.

The structures of PBRs have an important effect on $\mathrm{CO}_{2}$ fixation efficiency because they affect $\mathrm{CO}_{2}$ dissolution efficiency and $\mathrm{CO}_{2}$ utilization efficiency by microalgae (Li et al., 2013). Openculture systems normally cannot use supplied $\mathrm{CO}_{2}$ effectively, which easily escaped from the culture media due to the shallow depths and poor $\mathrm{CO}_{2}$ mass transfer efficiency, and $\mathrm{CO}_{2}$ fixation efficiency ranged from 10 to $30 \%$ (Weissman et al., 1988). Carbon fixation would be increased only when the $\mathrm{CO}_{2}$ residence time was increased in bioreactors (Cheng et al., 2006). Compared with open-culture systems, closed PBRs could reduce $\mathrm{CO}_{2}$ losses because they could prolong $\mathrm{CO}_{2}$ retention time and improve mass transfer efficiency. Ketheesan and Nirmalakhandan (2012) designed an airlift-driven raceway reactor for microalgal cultivation with the maximum $\mathrm{CO}_{2}$ utilization efficiency of $33 \%$. In order to enhance $\mathrm{CO}_{2}$ mass transfer rate as well as alleviate dissolved oxygen (DO) accumulation, a novel gas sparger of bubble tank was adopted in a PBR and the maximum $\mathrm{CO}_{2}$ removal efficiency reached $94 \%$ (Chai and Zhao, 2012). Fan et al. (2008) also designed a membrane-sparged helical tubular PBR for carbon dioxide biofixation by $C$. vulgaris. Thus, microalgae $\mathrm{CO}_{2}$ fixation with closed PBRs was a better choice (Li et al., 2013). 
A practical operation in which the flue gas from coke oven of steel plant directly supplied the carbon source for biomass production of the microalgal strain has been demonstrated (Chiu et al., 2011). An isolated thermal- and $\mathrm{CO}_{2}$-tolerant strain, Chlorella sp. MTF-7, was isolated by chemical mutagenesis. The flue gas, which contained approximately $25 \% \mathrm{CO}_{2}, 4 \% \mathrm{O}_{2}, 80 \mathrm{ppm} \mathrm{NO}$, and $90 \mathrm{ppm} \mathrm{SO}_{2}$, generated from coke oven of a steel plant was introduced into the microalgal cultures in a double-set PBR system by suction pump and air was supplied by an air pump. Chlorella sp. MTF-7 could be cultured with intermittent flue gas aeration controlled by a gas-switching cycle operation. For intermittent flue gas aeration, the flue gas was supplied in 30-min intervals every hour for $9 \mathrm{~h}$ during the day; a gas-switching cycle was performed with a flue gas inlet load for $30 \mathrm{~min}$ followed by an air inlet load for $30 \mathrm{~min}$. The intermittent flue gas aeration strategy and high initial density $(0.5 \mathrm{~g} / \mathrm{L})$ of Chlorella sp. overcome the environmental stress induced by high flue gases $\left(\mathrm{CO}_{2}, \mathrm{NO}, \mathrm{SO}_{2}\right)$ aeration and enhance microalgal growth. Besides, average efficiency of $\mathrm{CO}_{2}$ removal from the flue gas could reach $60 \%$, and $\mathrm{NO}$ and $\mathrm{SO}_{2}$ removal efficiency was maintained at approximately 70 and 50\%, respectively.

\section{Removal of $\mathrm{NO}_{x}$ by microalgae cultivation}

Besides $\mathrm{CO}_{2}$, flue gases contain different $\mathrm{NO}_{\mathrm{x}}$ species restricted by legislation and needed to remove in an additional gas treatment step such as chemical reduction and adsorption. NO is the major $\mathrm{NO}_{\mathrm{x}}$ species present, comprising about 90-95\% (Fritz and Pitchon, 1997). As nitrogen is one of the most important nutrients for algal production, a point of interest is that the $\mathrm{NO}_{\mathrm{x}}$ can serve as a nitrogen source for microalgae cultivation and can be metabolized by microalgae compared to the requirement of expensive catalysts or adsorbents (Cant and Liu, 2000). Thus, biological denox (bio-denox) method by microalgae may be a method worthy of promotion for flue gases treatment to reduce $\mathrm{NO}_{\mathrm{x}}$ emissions and merits further studies.

$\mathrm{NO}_{\mathrm{x}}$ removal efficiencies varied among microalgae strains. Some microalgae species such as Chlorella sp., Scenedesmus sp. (Jin et al., 2008; Santiago et al., 2010), and D. tertiolecta (Nagase et al., 1998,2001 ) had shown the possibility to bio-remove $\mathrm{NO}_{\mathbf{x}}$. Nagase et al. (1997) reported that an NO removal yield of approximately $65 \%$ by using the unicellular microalga $D$. tertiolecta when a model flue gas [100 ppm (v/v) $\mathrm{NO}$ and $15 \%(\mathrm{v} / \mathrm{v}) \mathrm{CO}_{2}$ in $\mathrm{N}_{2}$ ] at a flow rate of $150 \mathrm{~mL} / \mathrm{min}(0.0375 \mathrm{vvm})$ was supplied to the algal culture at an initial cell density of $0.7 \mathrm{~g} / \mathrm{L}$ cell dry weight. In addition, when a gas mixture containing $300 \mathrm{ppm}$ NO was treated through the Scenedesmus culture containing $5 \mathrm{mM}$ Fe(II)EDTA, a constant level of $80-85 \%$ NO removal was achieved for a prolonged period. For microalgal NO-elimination, NO gas is first dissolved in the aqueous phase, after which it is oxidized to nitrite and nitrate coupled with dissolved oxygen and then assimilated by microalgae cell. Some researches have reported that the rate-limiting step in reactor system for $\mathrm{NO}$-elimination is the dissolution of $\mathrm{NO}$ into the algae culture (Matsumoto et al., 1997; Niu and Leung, 2010). Attempts have been reported that enhance the solubility of NO gas by using efficient complexing agent like metal-chelated EDTA (Jin et al., 2008) or optimizing the reactor system structure (Nagase et al., 1998, 2001).

\section{Wastewater treatment by microalgae cultivation}

In the pilot scale of microalgae culture, the use of huge amounts of potable water is a serious problem, which would compete with land crops and human activities. Large amounts of nitrogen and phosphorus, which can be recovered from wastewater, are also required, but their cost in pure chemical form is high and their sustainability is low (Lardon et al., 2009). Consequently, microalgae production using wastewater as the nutrient source is a potential method, which offers added environmental advantages. The production of microalgae is effective in removing nitrogen, phosphorus, and toxic metals from a wide variety of wastewaters, producing cleaner effluents with high concentrations of dissolved oxygen (Gomez et al., 2013). However, it can not be ignored that there are a large number of endogenous bacteria in a real wastewater system affecting the growth of microalgae.

Cabanelas et al. (2013) used C. vulgaris for nitrogen and phosphorus removal from municipal wastewater with the highest removal rates of $9.8(\mathrm{~N})$ and $3.0(\mathrm{P}) \mathrm{mg} / \mathrm{L} /$ day. Other microalgae widely used for nutrient removal from different wastewater streams are Chlorella sp. (Gonzales et al., 1997; Cabanelas et al., 2013), Scenedesmus sp. (Martınez et al., 2000), and B. braunii (Álvarez-Díaz et al., 2013). Due to the complex characteristics of wastewater, the tests of growing algae in wastewater are mostly at laboratory scale. Pilot-scale algae cultivation continues to face many issues including contamination, inconsistent wastewater components, and unstable biomass production (Cai et al., 2013).

\section{Integrated environmental pollution control and biodiesel production by microalgae cultivation}

The capital and operating costs of algae-based biodiesel are still higher than petrol diesel, which encumber the development of microalgae biodiesel technology being commercial scale (Singh and Olsen, 2011; Singh et al., 2011a). Recently, some research results suggest that dual-use microalgae cultivation for environmental pollution control (especially wastewater treatment) coupling with biofuel generation is an attractive option in terms of reducing the energy cost, $\mathrm{CO}_{2}$ emissions, and nutrient and freshwater resource costs (Sun et al., 2013b). Zhou et al. (2012) developed an effective hetero-autotrophic mode for improved wastewater nutrient removal, wastewater recycling, and enhanced algal lipid accumulation with Auxenochlorella protothecoides UMN280. The maximal biomass concentration and lipids content reached $1.16 \mathrm{~g} / \mathrm{L}$ and $33.22 \%$ dry weight (DW). And the nutrient removal efficiencies for total phosphorus, ammonia, and nitrogen at the end of the two-stage cultivation were 98.48, 100 , and $90.60 \%$, respectively. Similar levels of total lipid content $(38.72 \%$ DW) have been observed in Chlorella pyrenoidosa grown in wastewater from fermentation effluent in Riboflavin process. The study of Li et al. (2011) showed that by the end of a 14-day batch culture Chlorella sp. could remove ammonia, total nitrogen, total phosphorus, and chemical oxygen demand (COD) in raw centrate, a highly concentrated municipal wastewater stream generated from activated sludge thickening process, by $93.9,89.1,80.9$, and $90.8 \%$, respectively. The FAME content was $11.04 \%$ of dry biomass, providing a biodiesel yield of $0.12 \mathrm{~g}$-biodiesel/L-algae culture solution. Therefore, further exploration is needed for improved wastewater treatment and 
cost-effective microalgae-based biodiesel feedstock production (Zhou et al., 2012).

\section{MICROALGAE FINE BIOLOGICAL REAGENT AND BIOACTIVE SUBSTANCES}

Besides biodiesel, various high-value chemical compounds such as pigments, antioxidants, $\beta$-carotenes, polysaccharides, vitamins, and biomass can be extracted from microalgae, and they are largely used as bulk commodities in different industrial sectors (e.g., pharmaceuticals, cosmetics, nutraceuticals, functional foods) (Mata et al., 2010). $\beta$-carotene, a vitamin A precursor in health food was the first high-value product commercially produced from Dunaliella bardawil. The biomass of microalgae as sun-dried or spray-dried powder or in compressed form as pastilles, which can be sold mostly in the human health food market is the predominant product in microalgal biotechnology. The final product of biomass production was also used both in aquaculture and animal husbandry as animal nutrition (Pulz and Gross, 2004). In addition, marine algae are considered as valuable sources of structurally diverse bioactive compounds such as hydrocolloids alginate, agar, and carrageenan. Ngo and Kim (2013) reported that marine algae are rich in sulfated polysaccharides (SPs) such as carrageenans in red algae (Rhodophyta), fucoidans in brown algae (Phaeophyta), and ulvans in green algae (Chlorophyta). These SPs exhibit many health beneficial nutraceutical effects such as antioxidant, antiallergic, anti-human immunodeficiency virus, anticancer, and anticoagulant activities (Borowitzka, 2013; Lin, 2013).

\section{FUTURE PERSPECTIVE}

Nowadays, rapid depletion of fossil fuels and rising GHG emissions has made microalgae as a biofuel source even more compelling. Moreover, lots of researches have demonstrated that microalgae biodiesel is technically feasible. Nevertheless, there is no current industrial production of algae biodiesel in the world. The higher capital and operating costs of microalgae farming compared to conventional agriculture, the non-sufficiently positive energy balance (after accounting for energy requirements for water, mixing, $\mathrm{CO}_{2}$ and nutrient supply, biomass harvesting and processing), and the not yet established sustainability still prevent the development of microalgae biodiesel technology being commercial scale (Zittelli et al., 2013).

The cost for microalgal biodiesel production may be balanced in the future by the following: first, cost of the raw materials (generally nitrogen and phosphorus sources, enriched $\mathrm{CO}_{2}$ supply, water) needs to reduce. Biodiesel production from microalgae can be more environmentally sustainable, cost-effective, and profitable if combined with processes such as wastewater and flue gas treatments. In other words, freshwater replace with wastewater, and flue gases were used as a carbon and inorganic nutrient source for culturing microalgae. One option is to locate algal ponds or PBRs near nutrient-rich wastewater streams, or by using feed sources such as anaerobic digester waste effluents. In order to achieve improved wastewater treatment and low-cost algal biomass as biofuel feedstock, an effective hetero-autotrophic mode was developed by Zhou et al. (2012). The culture process was separated into two independent parts. In the first stage, a heterotrophic-dominated mode using organic carbon in "Centrate" (a stream, generated through dewatering of sludge from primary and secondary settling) was for maximal cell density and lipid accumulation. The algae were harvested by self-sedimentation, and the residual wastewater was reused as medium for cultivation of the same strain. Then, an autotrophic dominated stage where $\mathrm{CO}_{2}$-rich flue gas during combustion could be sequestered by sparging into an algae PBR can be to further remove nutrients in the recycled wastewater. This strategy creates a process of combining wastewater treatment and $\mathrm{CO}_{2}$ fixation, while using the energy stored within the waste algal biomass could help to run the production process. Recent studies have shown that it is technically feasible to utilize $\mathrm{CO}_{2}$ from flue gases as carbon source to culture microalgae. However, latest research on $\mathrm{NO}_{\mathrm{x}}$ and $\mathrm{SO}_{\mathrm{x}}$ uptake by microalgae has been limited to a few publications. It is still unclear that acidic gases $\left(\mathrm{CO}_{2}, \mathrm{NO}_{\mathrm{x}}\right.$, and $\left.\mathrm{SO}_{\mathrm{x}}\right)$ in the flue gas uptake pathways by microalgae. In this regard, genetic engineering will have an important role in enhancing the overall life cycle of microalgae that are used as biofuels feedstock. Genetic modified microalgae that have the capability to grow under high concentration of $\mathrm{CO}_{2}$, able to tolerate other components in flue gases or wastewaters, and could produce high lipid content within their cells may be created. Advancement in this research area is urgently required to bring a significant breakthrough in producing greener and sustainable microalgae biofuels.

Second, continuous technical breakthrough will be required to improve efficiency. For the downstream processes, energy consumption is a big concern in microalga biomass harvesting, and lipid extraction. When considering chemical, physical, and biological harvesting methods, each method has its advantages and limits. Developing hybrid techniques, which make use of all harvesting categories, may be a viable option that is worth exploring. The comparison also highlights the fact that none of the harvesting methods are cost-effective when considering cultivation of microalgae solely for biodiesel production. Hence, it is a necessity to fine by-products that has a higher market value. In addition, direct transesterification and wet lipid extraction/transesterification, which are important innovations in the algae lipid extraction and biodiesel conversion arena, are yet to be discovered to develop the optimum utilization of algal biomass for the commercial production of biofuel.

Finally, the bio-refining of microalgae is to increase the economic benefit for microalgal biodiesel production. The applications of algal biorefinery could possibly range from direct usage of biomass for food to high value-added products such as antioxidants and $\beta$-carotenes, and ecological applications such as wastewater and flue gas treatments. Glycerol, one of the main byproducts of the transesterification process, can serve as a carbon feedstock for heterotrophic algal growth. Grown on crude glycerol, C. protothecoides has delivered biomass and lipid yields similar to growth on glucose (Chen and Walker, 2011; Georgianna and Mayfield, 2012). The cost of microalgal biodiesel could be substantially reduced when coupled with any of the biorefinery-based production strategies.

\section{ACKNOWLEDGMENTS}

This work was supported jointly by the National Program on Key Basic Research Project (2012CB224803), the National Natural 
Science Foundation of China (31300030), Sinopec (S213049), the Natural Science Foundation of Hubei Province of China (2013CFA109), and the Knowledge Innovation Program of the Chinese Academy of Sciences (Y35E05).

\section{REFERENCES}

Abu-Khader, M. M. (2006). Recent progress in $\mathrm{CO}_{2}$ capture/sequestration: a review. Energy Sources Part A 28, 1261-1279. doi:10.1080/009083190933825

Ahmad, A. L., Yasin, N. H. M., Derek, C. J. C., and Lim, J. K. (2014a). Comparison of harvesting methods for microalgae Chlorella sp. and its potential use as a biodiesel feedstock. Environ. Technol. 35, 2244-2253. doi:10.1080/09593330. 2014.900117

Ahmad, A. L., Yasin, N. H. M., Derek, C. J. C., and Lim, J. K. (2014b). Kinetic studies and thermodynamics of oil extraction and transesterification of Chlorella $\mathrm{sp}$ for biodiesel production. Environ. Technol. 35, 891-897. doi:10.1080/09593330. 2013.855263

Álvarez-Díaz, P. D., Ruiz, J., Arbib, Z., Barragán, J., Garrido-Pérez, C., and Perales, J. A. (2013). Factorial analysis of the biokinetic growth parameters and CO2 fixation rate of Chlorella vulgaris and Botryococcus brauniii waste water and synthetic medium. Desalination Water Treat. 34, 1-11. doi:10.1080/19443994.2013.808590

Amaro, H. M., Guedes, A. C., and Malcata, F. X. (2011). Advances and perspectives in using microalgae to produce biodiesel. Appl. Energy 88, 3402-3410. doi:10.1111/j.1365-313X.2008.03492.x

Andrich, G., Zinnai, A., Nesti, U., and Venturi, F. (2006). Supercritical fluid extraction of oil from microalga Spirulina (Arthrospira) platensis. Acta Aliment. 35, 195-203. doi:10.1556/AAlim.35.2006.2.6

Arbib, Z., Ruiz, J., Alvarez-Diaz, P., Garrido-Perez, C., Barragan, J., and Perales, J. A. (2013). Long term outdoor operation of a tubular airlift pilot photobioreactor and a high rate algal pond as tertiary treatment of urban wastewater. Ecol. Eng. 52, 143-153. doi:10.1016/j.ecoleng.2012.12.089

Arias-Penaranda, M. T., Cristiani-Urbina, E., Montes-Horcasitas, C., Esparza-Garcia, F., Torzillo, G., and Canizares-Villanueva, R. (2013). Scenedesmus incrassatulus CLHE-Si01: a potential source of renewable lipid for high quality biodiesel production. Bioresour. Technol. 140, 158-164. doi:10.1016/j.biortech.2013.04.080

Benemann, J. R. (1993). Utilization of carbon dioxide from fossil fuel-burning power plants with biological systems. Energy Convers. Manag. 34, 999-1004. doi:10.1016/0196-8904(93)90047-E

Beuckels, A., Depraetere, O., Vandamme, D., Foubert, I., Smolders, E., and Muylaert, K. (2013). Influence of organic matter on flocculation of Chlorella vulgaris by calcium phosphate precipitation. Biomass Bioeng. 54, 107-114. doi:10.1016/j.biombioe.2013.03.027

Biondi, N., Bassi, N., Zittelli, G. C., De Faveri, D., Giovannini, A., Rodolfi, L., et al. (2013). Nannochloropsis sp F\&M-M24: oil production, effect of mixing on productivity and growth in an industrial wastewater. Environ. Prog. Sustain. Energy 32, 846-853. doi:10.1002/ep.11681

Bligh, E. G., and Dyer, W. J. (1959). A rapid method of total lipid extraction and purification. Can. J. Biochem. Physiol. 37, 911-917. doi:10.1139/y59-099

Bogen, C., Klassen, V., Wichmann, J., La Russa, M., Doebbe, A., Grundmann, M., et al. (2013). Identification of Monoraphidium contortum as a promising species for liquid biofuel production. Bioresour. Technol. 133, 622-626. doi:10.1016/j.biortech.2013.01.164

Borowitzka, M. A. (2013). High-value products from microalgae-their development and commercialisation. J. Appl. Phycol. 25, 743-756. doi:10.1007/s10811-0139983-9

Borowitzka, M. A., and Moheimani, N. R. (2013). Sustainable biofuels from algae. Mitig. Adapt. Strat. Gl. 18, 13-25. doi:10.1007/s11027-010-9271-9

Cabanelas, I. T. D., Ruiz, J., Arbib, Z., Chinalia, F. A., Garrido-Perez, C., Rogalla, F., et al. (2013). Comparing the use of different domestic wastewaters for coupling microalgal production and nutrient removal. Bioresour. Technol. 131, 429-436. doi:10.1016/j.biortech.2012.12.152

Cai, T., Park, S. Y., and Li, Y. (2013). Nutrient recovery from wastewater streams by microalgae: status and prospects. Renew. Sustain. Energ. Rev. 19, 360-369. doi:10.1016/j.rser.2012.11.030

Canakci, M. (2007). The potential of restaurant waste lipids as biodiesel feedstocks. Bioresour. Technol. 98, 183-190. doi:10.1016/j.biortech.2005.11.022

Cant, N. W., and Liu, I. O. (2000). The mechanism of the selective reduction of nitrogen oxides by hydrocarbons on zeolite catalysts. Catal. Today 63, 133-146. doi:10.1021/es203070g
Chai, X., and Zhao, X. (2012). Enhanced removal of carbon dioxide and alleviation of dissolved oxygen accumulation in photobioreactor with bubble tank. Bioresour. Technol. 116, 360-365. doi:10.1016/j.biortech.2012.03.105

Chaumont, D. (1993). Biotechnology of algal biomass production: a review of systems for outdoor mass culture. J. Appl. Phycol. 5, 593-604. doi:10.1007/ BF02184638

Chen, C. Y., Yeh, K. L., Aisyah, R., Lee, D. J., and Chang, J. S. (2011a). Cultivation, photobioreactor design and harvesting of microalgae for biodiesel production: a critical review. Bioresour. Technol. 102,71-81. doi:10.1016/j.biortech.2010.06.159

Chen, M., Chen, X., Liu, T., and Zhang, W. (2011b). Subcritical ethanol extraction of lipid from wet microalgae paste of Nannochloropsis sp. J. Biobased Mater. Bioenergy 5, 385-389. doi:10.1166/jbmb.2011.1157

Chen, F. (1996). High cell density culture of microalgae in heterotrophic growth. Trends Biotechnol. 14, 421-426. doi:10.1016/0167-7799(96)10060-3

Chen, H., Zhang, Y., He, C., and Wang, Q. (2014). Ca2+ signal transduction related to neutral lipid synthesis in an oil-producing green alga Chlorella sp. C2. Plant Cell Physiol. 55, 634-644. doi:10.1093/pcp/pcu015

Chen, L., Liu, T., Zhang, W., Chen, X., and Wang, J. (2012). Biodiesel production from algae oil high in free fatty acids by two-step catalytic conversion. Bioresour. Technol. 111, 208-214. doi:10.1016/j.biortech.2012.02.033

Chen, Y., Wang, J. F., Zhang, W., Chen, L., Gao, L. L., and Liu, T. Z. (2013). Forced light/dark circulation operation of open pond for microalgae cultivation. Biomass Bioeng. 56, 464-470. doi:10.1016/j.biombioe.2013.05.034

Chen, Y. H., and Walker, T. H. (2011). Biomass and lipid production of heterotrophic microalgae Chlorella protothecoides by using biodiesel-derived crude glycerol. Biotechnol. Lett. 33, 1973-1983. doi:10.1007/s10529-011-0672-y

Cheng, L., Zhang, L., Chen, H., and Gao, C. (2006). Carbon dioxide removal from air by microalgae cultured in a membrane-photobioreactor. Sep. Purif. Technol. 50, 324-329. doi:10.1016/j.seppur.2005.12.006

Chisti, Y. (2007). Biodiesel from microalgae. Biotechnol. Adv. 25, 294-306. doi:10. 1016/j.biotechadv.2007.02.001

Chiu, S.-Y., Kao, C.-Y., Huang, T.-T., Lin, C.-J., Ong, S.-C., Chen, C.-D., et al. (2011). Microalgal biomass production and on-site bioremediation of carbon dioxide, nitrogen oxide and sulfur dioxide from flue gas using Chlorella sp. cultures. Bioresour. Technol. 102, 9135-9142. doi:10.1016/j.biortech.2011.06.091

Chojnacka, K. (2004). Kinetic and stoichiometric relationships of the energy and carbonmetabolism in the culture of microalgae. Biotechnology 3, 21-34. doi:10.3923/biotech.2004.21.34

Dang-Thuan, T., Chen, C. L., and Chang, J. S. (2013). Effect of solvents and oil content on direct transesterification of wet oil-bearing microalgal biomass of Chlorella vulgaris ESP-31 for biodiesel synthesis using immobilized lipase as the biocatalyst. Bioresour. Technol. 135, 213-221. doi:10.1016/j.biortech.2012. 09.101

De Baerdemaeker, T., Lemmens, B., Dotremont, C., Fret, J., Roef, L., Goiris, K., et al. (2013). Benchmark study on algae harvesting with backwashable submerged flat panel membranes. Bioresour. Technol. 129, 582-591. doi:10.1016/j.biortech.2012. 10.153

de-Bashan, L. E., and Bashan, Y. (2010). Immobilized microalgae for removing pollutants: review of practical aspects. Bioresour. Technol. 101, 1611-1627. doi:10.1016/j.biortech.2009.09.043

Demirbas, A. (2008). Production of biodiesel from algae oils. Energy Sources Part A 31, 163-168. doi:10.1080/15567030701521775

Dote, Y., Sawayama, S., Inoue, S., Minowa, T., and Yokoyama, S.-Y. (1994). Recovery of liquid fuel from hydrocarbon-rich microalgae by thermochemical liquefaction. Fuel 73, 1855-1857. doi:10.1016/0016-2361(94)90211-9

Doucha, J., and Lívanský, K. (2006). Productivity, $\mathrm{CO}_{2} / \mathrm{O}_{2}$ exchange and hydraulics in outdoor open high density microalgal (Chlorella sp.) photobioreactors operated in a Middle and Southern European climate. J. Appl. Phycol. 18, 811-826. doi:10.1007/s10811-006-9100-4

Doucha, J., Straka, F., and Lívanský, K. (2005). Utilization of flue gas for cultivation of microalgae Chlorella sp. in an outdoor open thin-layer photobioreactor. J. Appl. Phycol. 17, 403-412. doi:10.1007/s10811-005-8701-7

Ebenezer, V., Medlin, L. K., and Ki, J.-S. (2012). Molecular detection, quantification, and diversity evaluation of microalgae. Mar. Biotechnol. 14, 129-142. doi:10.1007/s10126-011-9427-y

El-Sheekh, M., Abomohra, A., and Hanelt, D. (2013). Optimization of biomass and fatty acid productivity of Scenedesmus obliquus as a promising microalga for biodiesel production. World J. Microbiol. Biotechnol. 29, 915-922. doi:10.1007/ s11274-012-1248-2 
Fan, L.-H., Zhang, Y.-T., Zhang, L., and Chen, H.-L. (2008). Evaluation of a membrane-sparged helical tubular photobioreactor for carbon dioxide biofixation by Chlorella vulgaris. J. Memb. Sci. 325, 336-345. doi:10.1016/j.memsci. 2008.07.044

Farrelly, D. J., Brennan, L., Everard, C. D., and McDonnell, K. P. (2014). Carbon dioxide utilisation of Dunaliella tertiolecta for carbon bio-mitigation in a semicontinuous photobioreactor. Appl. Microbiol. Biotechnol. 98, 3157-3164. doi:10.1007/s00253-013-5322-y

Francisco, E. C., Neves, D. B., Jacob-Lopes, E., and Franco, T. T. (2010). Microalgae as feedstock for biodiesel production: carbon dioxide sequestration, lipid production and biofuel quality. J. Chem. Technol. Biotechnol. 85, 395-403. doi: $10.1002 /$ jctb. 2338

Fritz, A., and Pitchon, V. (1997). The current state of research on automotive lean $\mathrm{NO}_{\mathrm{x}}$ catalysis. Appl. Catal. B Environ. 13, 1-25. doi:10.1016/S0926-3373(96) 00102-6

Garzon-Sanabria, A. J., Davis, R. T., and Nikolov, Z. L. (2012). Harvesting Nannochloris oculata by inorganic electrolyte flocculation: effect of initial cell density, ionic strength, coagulant dosage, and media pH. Bioresour. Technol. 118, 418-424. doi:10.1016/j.biortech.2012.04.057

Georgianna, D. R., and Mayfield, S. P. (2012). Exploiting diversity and synthetic biology for the production of algal biofuels. Nature 488, 329-335. doi:10.1038/nature11479

Ginzburg, B.-Z. (1993). Liquid fuel (oil) from halophilic algae: a renewable source of non-polluting energy. Renew. Energy 3, 249-252. doi:10.1016/0960-1481(93) 90031-B

Gomez, C., Escudero, R., Morales, M. M., Figueroa, F. L., Fernandez-Sevilla, J. M., and Acien, F. G. (2013). Use of secondary-treated wastewater for the production of Muriellopsis sp. Appl. Microbiol. Biotechnol. 97, 2239-2249. doi:10.1007/s00253-012-4634-7

Gonzales, L., Canizares, R., and Baena, S. (1997). Efficiency of ammonia and phosphorus removal from a Colombian agroindustrial wastewater by the microalgae Chlorealla vulgaris and Scenedesmus dimorphus. Bioresour. Technol. 60, 259-262. doi:10.1016/S0960-8524(97)00029-1

Gouveia, L., Nobre, B., Marcelo, F., Mrejen, S., Cardoso, M., Palavra, A., et al. (2007). Functional food oil coloured by pigments extracted from microalgae with supercritical $\mathrm{CO}_{2}$. Food Chem. 101, 717-723. doi:10.1016/j.foodchem.2006.02.027

Grima, E. M., Belarbi, E. H., Fernandez, F. G. A., Medina, A. R., and Chisti, Y. (2003). Recovery of microalgal biomass and metabolites: process options and economics. Biotechnol. Adv. 20, 491-515. doi:10.1016/S0734-9750(02)00050-2

Haq, I., Muhammad, A., and Hameed, U. (2014). Comparative assessment of Cladophora, Spirogyra and Oedogonium biomass for the production of fatty acid methyl esters. Appl. Biochem. Microbiol. 50, 69-72. doi:10.1134/ S0003683813060094

Harith, Z. T., Yusoff, F. M., Mohamed, M. S., Din, M. S. M., and Ariff, A. B. (2009). Effect of different flocculants on the flocculation performance of microalgae, Chaetoceros calcitrans, cells. Afr. J. Biotechnol. 8, 5971-5978.

Hernandez-Martin, E., and Otero, C. (2008). Different enzyme requirements for the synthesis of biodiesel: Novozym (R) 435 and Lipozyme (R) TL IM. Bioresour. Technol. 99, 277-286. doi:10.1016/j.biortech.2006.12.024

Hidalgo, P., Toro, C., Ciudad, G., and Navia, R. (2013). Advances in direct transesterification of microalgal biomass for biodiesel production. Rev. Environ. Sci. Biotechnol. 12, 179-199. doi:10.1007/s11157-013-9308-0

Hsueh, H. T., Chu, H., and Yu, S. T. (2007). A batch study on the bio-fixation of carbon dioxide in the absorbed solution from a chemical wet scrubber by hot spring and marine algae. Chemosphere 66, 878-886. doi:10.1016/j.chemosphere. 2006.06.022

Hu, Q., Sommerfeld, M., Jarvis, E., Ghirardi, M., Posewitz, M., Seibert, M., et al. (2008). Microalgal triacylglycerols as feedstocks for biofuel production: perspectives and advances. Plant J. 54, 621-639. doi:10.1111/j.1365-313X.2008. 03492. $\mathrm{x}$

Iancu, P., Plesu, V., and Velea, S. (2012). "Flue gas $\mathrm{CO}_{2}$ capture by microalgae in photobioreactor: a sustainable technology," in 2012: 15th International Conference on Process Integration, Modelling and Optimisation for Energy Saving and Pollution Reduction, Vol. 29, eds P. S. Varbanov, H. L. Lam, J. J. Klemes, and S. Pierucci (Milano: Aidic Servizi Srl), 799-804.

International Energy Agency, X. (2013a). Energy Technology Initiatives 2013. Paris: IEA.

International Energy Agency, Y. (2013b). Key World Energy Statistics 2013. Paris: IEA.
International Energy Agency, Z. (2013c). $\mathrm{CO}_{2}$ Emissions from Fuel Combustion Highlights 2013. Paris: IEA.

Jiang, Y., Zhang, W., Wang, J., Chen, Y., Shen, S., and Liu, T. (2013). Utilization of simulated flue gas for cultivation of Scenedesmus dimorphus. Bioresour. Technol. 128, 359-364. doi:10.1016/j.biortech.2012.10.119

Jin, H.-F., Santiago, D. E. O., Park, J., and Lee, K. (2008). Enhancement of nitric oxide solubility using Fe(II)EDTA and its removal by green algae Scenedesmus sp. Biotechnol. Bioprocess Eng. 13, 48-52. doi:10.1007/s12257-007-0164-z

Kanda, H., Li, P., Yoshimura, T., and Okada, S. (2013). Wet extraction of hydrocarbons from Botryococcus braunii by dimethyl ether as compared with dry extraction by hexane. Fuel 105, 535-539. doi:10.1016/i.fuel.2012.08.032

Ketheesan, B., and Nirmalakhandan, N. (2012). Feasibility of microalgal cultivation in a pilot-scale airlift-driven raceway reactor. Bioresour. Technol. 108, 196-202. doi:10.1016/j.biortech.2011.12.146

Kim, J., Ryu, B.-G., Kim, K., Kim, B.-K., Han, J.-I., and Yang, J.-W. (2012). Continuous microalgae recovery using electrolysis: effect of different electrode pairs and timing of polarity exchange. Bioresour. Technol. 123, 164-170. doi:10.1016/j.biortech.2012.08.010

Kim, S. G., Choi, A., Ahn, C. Y., Park, C. S., Park, Y. H., and Oh, H. M. (2005). Harvesting of Spirulina platensis by cellular flotation and growth stage determination. Lett. Appl. Microbiol. 40, 190-194. doi:10.1111/j.1472-765X.2005.01654.x

Kumar, A., Ergas, S., Yuan, X., Sahu, A., Zhang, Q., Dewulf, J., et al. (2010). Enhanced $\mathrm{CO} 2$ fixation and biofuel production via microalgae: recent developments and future directions. Trends Biotechnol. 28, 371-380. doi:10.1016/j.tibtech.2010.04. 004

Lam, M. K., and Lee, K. T. (2012). Microalgae biofuels: a critical review of issues, problems and the way forward. Biotechnol. Adv. 30, 673-690. doi:10.1016/j. biotechadv.2011.11.008

Lam, M. K., Lee, K. T., and Mohamed, A. R. (2010). Homogeneous, heterogeneous and enzymatic catalysis for transesterification of high free fatty acid oil (waste cooking oil) to biodiesel: a review. Biotechnol. Adv. 28, 500-518. doi:10.1016/j.biotechadv.2010.03.002

Lardon, L., Hélias, A., Sialve, B., Steyer, J.-P., and Bernard, O. (2009). Life-cycle assessment of biodiesel production from microalgae. Environ. Sci. Technol. 43, 6475-6481. doi:10.1021/es900705j

Lee, J. H., Lee, J. S., Shin, C. S., Park, S. C., and Kim, S. W. (2000). Effects of NO and $\mathrm{SO} 2$ on growth of highly- $\mathrm{CO}_{2}$-tolerant microalgae. J. Microbiol. Biotechnol. 10, 338-343.

Lee, O. K., Kim, Y. H., Na, J.-G., Oh, Y.-K., and Lee, E. Y. (2013a). Highly efficient extraction and lipase-catalyzed transesterification of triglycerides from Chlorella sp KR-1 for production of biodiesel. Bioresour. Technol. 147, 240-245. doi:10.1016/j.biortech.2013.08.037

Lee, Y. C., Kim, B., Farooq, W., Chung, J., Han, J. I., Shin, H. J., et al. (2013b). Harvesting of oleaginous Chlorella sp by organoclays. Bioresour. Technol. 132, 440-445. doi:10.1016/j.biortech.2013.01.102

Lee, Y. K. (2007). "Algal nutrition - heterotrophic carbon nutrition," in Handbook of Microalgal Culture: Biotechnology and Applied Phycology, ed. A. Richmond (Oxford, UK: Blackwell Publishing Ltd), 116-124. doi:10.1002/9780470995280. ch7

Li, S. W., Luo, S. J., and Guo, R. B. (2013). Efficiency of $\mathrm{CO}_{2}$ fixation by microalgae in a closed raceway pond. Bioresour. Technol. 136, 267-272. doi:10.1016/j.biortech. 2013.03.025

Li, Y., Chen, Y.-F., Chen, P., Min, M., Zhou, W., Martinez, B., et al. (2011). Characterization of a microalga Chlorella sp. well adapted to highly concentrated municipal wastewater for nutrient removal and biodiesel production. Bioresour. Technol. 102, 5138-5144. doi:10.1016/j.biortech.2011.01.091

Lin, S.-K. (2013). Marine nutraceuticals: prospects and perspectives. By Se-Kwon Kim, CRC Press, 2013; 464 Pages. Price 108.00, ISBN 978-1-4665-1351-8. Mar. Drugs 11, 1300-1303. doi:10.3390/md11041300

Liu, X., He, H., Wang, Y., and Zhu, S. (2007). Transesterification of soybean oil to biodiesel using SrO as a solid base catalyst. Catal. Commun. 8, 1107-1111. doi:10.1021/jp9039379

Liu, Z., Zhang, F., and Chen, F. (2013). High throughput screening of $\mathrm{CO}_{2}$-tolerating microalgae using GasPak bags. Aquat. Biosyst. 9, 23. doi:10.1186/2046-9063-9-23

Makareviciene, V., Skorupskaite, V., Levisauskas, D., Andruleviciute, V., and Kazancev, K. (2014). The optimization of biodiesel fuel production from microalgae oil using response surface methodology. Int. J. Green Energy 11, 527-541. doi:10.1080/15435075.2013.777911 
Mandal, S., Patnaik, R., Singh, A. K., and Mallick, N. (2013). Comparative assessment of various lipid extraction protocols and optimization of transesterification process for microalgal biodiesel production. Environ. Technol. 34, 2009-2018. doi:10.1080/09593330.2013.827730

Martınez, M., Sánchez, S., Jiménez, J., El Yousfi, F., and Munoz, L. (2000). Nitrogen and phosphorus removal from urban wastewater by the microalga Scenedesmus obliquus. Bioresour. Technol. 73, 263-272. doi:10.1016/j.jbiotec.2014.03.001

Mata, T. M., Martins, A. A., and Caetano, N. S. (2010). Microalgae for biodiesel production and other applications: a review. Renew. Sust. Energy Rev. 14, 217-232. doi:10.1016/j.rser.2009.07.020

Matsumoto, H., Hamasaki, A., Sioji, N., and Ikuta, Y. (1997). Influence of $\mathrm{CO}_{2}, \mathrm{SO}_{2}$ and NO in flue gas on microalgae productivity. J. Chem. Eng. Jpn. 30, 620-624. doi:10.1252/jcej.30.620

Meher, L., Vidya Sagar, D., and Naik, S. (2006). Technical aspects of biodiesel production by transesterification - a review. Renew. Sustain. Energ. Rev. 10, 248-268. doi:10.1016/j.rser.2004.09.002

Mendes, R. L., Fernandes, H. L., Coelho, J. A., Cabral, J. M., Palavra, A. M., and Novais, J. M. (1994). Supercritical carbon dioxide extraction of hydrocarbons from the microalga Botryococcus braunii. J. Appl. Phycol. 6, 289-293. doi:10.1007/BF02181941

Miao, X., and Wu, Q. (2006a). Biodiesel production from heterotrophic microalgal oil. Bioresour. Technol. 97, 841-846. doi:10.1016/j.biortech.2005.04.008

Miao, X. L., and Wu, Q. Y. (2006b). Biodiesel production from heterotrophic microalgal oil. Bioresour. Technol. 97, 841-846. doi:10.1016/j.biortech.2005.04. 008

Milledge, J., and Heaven, S. (2013). A review of the harvesting of micro-algae for biofuel production. Rev. Environ. Sci. Biotechnol. 12, 165-178. doi:10.1007/s11157012-9301-z

Moazami, N., Ashori, A., Ranjbar, R., Tangestani, M., Eghtesadi, R., and Nejad, A. S. (2012). Large-scale biodiesel production using microalgae biomass of Nannochloropsis. Biomass Bioeng. 39, 449-453. doi:10.1016/j.biombioe.2012.01.046

Molina Grima, E., Belarbi, E. H., Acien Fernandez, F. G., Robles Medina, A., and Chisti, Y. (2003). Recovery of microalgal biomass and metabolites: process options and economics. Biotechnol. Adv. 20, 491-515. doi:10.1016/S07349750(02)00050-2

Mouahid, A., Crampon, C., Toudji, S. A. A., and Badens, E. (2013). Supercritical CO2 extraction of neutral lipids from microalgae: experiments and modelling. J. Supercrit. Fluids 77, 7-16. doi:10.1016/j.supflu.2013.01.024

Nagase, H., Eguchi, K., Yoshihara, K., Hirata, K., and Miyamoto, K. (1998). Improvement of microalgal $\mathrm{NO}_{\mathrm{x}}$ removal in bubble column and airlift reactors. J. Ferment. Bioeng. 86, 421-423. doi:10.1016/S0922-338X(99)89018-7

Nagase, H., Yoshihara, K., Eguchi, K., Okamoto, Y., Murasaki, S., Yamashita, R., et al. (2001). Uptake pathway and continuous removal of nitric oxide from flue gas using microalgae. Biochem. Eng. J. 7, 241-246. doi:10.1016/S1369-703X(00) 00122-4

Nagase, H., Yoshihara, K., Eguchi, K., Yokota, Y., Matsui, R., Hirata, K., et al. (1997). Characteristics of biological $\mathrm{NO}_{\mathrm{x}}$ removal from flue gas in a Dunaliella tertiolecta culture system. J. Ferment. Bioeng. 83, 461-465. doi:10.1016/S0922-338X(97) 83001-2

Nakanishi, A., Aikawa, S., Ho, S.-H., Chen, C.-Y., Chang, J.-S., Hasunuma, T., et al. (2014). Development of lipid productivities under different CO2 conditions of marine microalgae Chlamydomonas sp. JSC4. Bioresour. Technol. 152, 247-252. doi:10.1016/j.biortech.2013.11.009

Nascimento, I. A., Marques, S. S. I., Cabanelas, I. T. D., Pereira, S. A., Druzian, J. I., de Souza, C. O., et al. (2013). Screening microalgae strains for biodiesel production: lipid productivity and estimation of fuel quality based on fatty acids profiles as selective criteria. Bioenerg. Res. 6, 1-13. doi:10.1007/s12155-012-9222-2

Neveux, N., Yuen, A. K. L., Jazrawi, C., Magnusson, M., Haynes, B. S., Masters, A. F., et al. (2014). Biocrude yield and productivity from the hydrothermal liquefaction of marine and freshwater green macroalgae. Bioresour. Technol. 155, 334-341. doi:10.1016/j.biortech.2013.12.083

Ngo, D.-H., and Kim, S.-K. (2013). Sulfated polysaccharides as bioactive agents from marine algae. Int. J. Biol. Macromol. 62, 70-75. doi:10.1016/j.ijbiomac.2013.08. 036

Nigam, P. S., and Singh, A. (2011). Production of liquid biofuels from renewable resources. Prog. Energy Combust. Sci. 37, 52-68. doi:10.1016/j.pecs.2010.01.003

Niu, H. J. Y., and Leung, D. Y. C. (2010). A review on the removal of nitrogen oxides from polluted flow by bioreactors. Environ. Rev. 18, 175-189. doi:10.1139/A10-007
Ogbonna, J. C., Ichige, E., and Tanaka, H. (2002). Regulating the ratio of photoautotrophic to heterotrophic metabolic activities in photoheterotrophic culture of Euglena gracilis and its application to $\alpha$-tocopherol production. Biotechnol. Lett. 24, 953-958. doi:10.1023/A:1015681105420

Oh, H. M., Lee, S. J., Park, M. H., Kim, H. S., Kim, H. C., Yoon, J. H., et al. (2001). Harvesting of Chlorella vulgaris using a bioflocculant from Paenibacillus sp AM49. Biotechnol. Lett. 23, 1229-1234. doi:10.1023/A:1012730522288

Perez-Garcia, O., Escalante, F. M. E., de-Bashan, L. E., and Bashan, Y. (2011). Heterotrophic cultures of microalgae: metabolism and potential products. Water Res. 45, 11-36. doi:10.1016/j.watres.2010.08.037

Phukan, M. M., Chutia, R. S., Konwar, B. K., and Kataki, R. (2011). Microalgae Chlorella as a potential bio-energy feedstock. Appl. Energy 88, 3307-3312. doi:10.1016/j.biortech.2013.11.059

Pires, J. C. M., Alvim-Ferraz, M. C. M., Martins, F. G., and Simoes, M. (2012). Carbon dioxide capture from flue gases using microalgae: engineering aspects and biorefinery concept. Renew. Sust. Energy Rev. 16, 3043-3053. doi:10.1016/j.rser. 2012.02.055

Pruvost, J., Van Vooren, G., Cogne, G., and Legrand, J. (2009). Investigation of biomass and lipids production with Neochloris oleoabundans in photobioreactor. Bioresour. Technol. 100, 5988-5995. doi:10.1016/j.biortech.2009.06.004

Pulz, O., and Gross, W. (2004). Valuable products from biotechnology of microalgae. Appl. Microbiol. Biotechnol. 65, 635-648. doi:10.1007/s00253-004-1647-x

Richmond, A. (ed.) (2008). Handbook of Microalgal Culture: Biotechnology and Applied Phycology. John Wiley \& Sons.

Salim, S., Bosma, R., Vermue, M. H., and Wijffels, R. H. (2011). Harvesting of microalgae by bio-flocculation. J. Appl. Phycol. 23, 849-855. doi:10.1007/s10811010-9591-x

Santiago, D. E., Jin, H.-F., and Lee, K. (2010). The influence of ferrous-complexed EDTA as a solubilization agent and its auto-regeneration on the removal of nitric oxide gas through the culture of green alga Scenedesmus sp. Process Biochem. 45, 1949-1953. doi:10.1016/j.procbio.2010.04.003

Sanyano, N., Chetpattananondh, P., and Chongkhong, S. (2013). Coagulationflocculation of marine Chlorella sp for biodiesel production. Bioresour. Technol. 147, 471-476. doi:10.1016/j.biortech.2013.08.080

Sathish, A., Smith, B. R., and Sims, R. C. (2014). Effect of moisture on in situ transesterification of microalgae for biodiesel production. J. Chem. Technol. Biotechnol. 89, 137-142. doi:10.1002/jctb.4125

Schipper, K., van der Gijp, S., van der Stel, R., and Goetheer, E. (2013). New methodologies for the integration of power plants with algae ponds. Energy Procedia 37, 6687-6695. doi:10.1016/j.egypro.2013.06.601

Scott, S. A., Davey, M. P., Dennis, J. S., Horst, I., Howe, C. J., Lea-Smith, D. J., et al. (2010). Biodiesel from algae: challenges and prospects. Curr. Opin. Biotechnol. 21, 277-286. doi:10.1016/j.copbio.2010.03.005

Sharif Hossain, A., Salleh, A., Boyce, A. N., Chowdhury, P., and Naqiuddin, M. (2008). Biodiesel fuel production from algae as renewable energy. Am. J. Biochem. Biotechnol. 4, 250-254.

Sharma, K. K., Garg, S., Li, Y., Malekizadeh, A., and Schenk, P. M. (2013). Critical analysis of current microalgae dewatering techniques. Biofuels 4, 397-407.

Simoneit, B., Rogge, W., Lang, Q., and Jaffé, R. (2000). Molecular characterization of smoke from campfire burning of pine wood (Pinus elliottii). Chemosphere Global Change Sci. 2, 107-122. doi:10.1016/S1465-9972(99)00048-3

Singh, A., and Olsen, S. I. (2011). A critical review of biochemical conversion, sustainability and life cycle assessment of algal biofuels. Appl. Energy 88, 3548-3555. doi:10.1016/j.apenergy.2010.12.012

Singh, A., Olsen, S. I., and Nigam, P. S. (2011a). A viable technology to generate third-generation biofuel. J. Chem. Technol. Biotechnol. 86, 1349-1353. doi:10.1002/jctb.2666

Singh, A., Nigam, P. S., and Murphy, J. D. (2011b). Mechanism and challenges in commercialisation of algal biofuels. Bioresour. Technol. 102, 26-34. doi:10.1016/ j.biortech.2010.06.057

Singh, A., Nigam, P. S., and Murphy, J. D. (2011c). Renewable fuels from algae: an answer to debatable land based fuels. Bioresour. Technol. 102, 10-16. doi:10.1016/j.biortech.2010.06.032

Singh, A., Pant, D., Olsen, S. I., and Nigam, P. S. (2012). Key issues to consider in microalgae based biodiesel production. Energy Educ. Sci. Technol. Part A Energy Sci. Res. 29, 687-700.

Soletto, D., Binaghi, L., Ferrari, L., Lodi, A., Carvalho, J., Zilli, M., et al. (2008). Effects of carbon dioxide feeding rate and light intensity on the fed-batch pulse-feeding 
cultivation of Spirulina platensis in helical photobioreactor. Biochem. Eng. J. 39, 369-375. doi:10.1016/j.bej.2007.10.007

Soxhlet, F. (1879). Die gewichtsanalytische bestimmung des milchfettes. Polytech. J. 232, 461-465.

Sun, X., Wang, C., Tong, Y., Wang, W., and Wei, J. (2013a). Microalgae filtration by UF membranes: influence of three membrane materials. Desalination Water Treat. 45, 1-8. doi:10.1080/19443994.2013.860629

Sun, X., Wang, C., Li, Z., Wang, W., Tong, Y., and Wei, J. (2013b). Microalgal cultivation in wastewater from the fermentation effluent in Riboflavin (B2) manufacturing for biodiesel production. Bioresour. Technol. 143, 499-504. doi:10.1016/j.biortech.2013.06.044

Talukder, M. M. R., Wu, J. C., Van Nguyen, T. B., Fen, N. M., and Melissa, Y. L. S. (2009). Novozym 435 for production of biodiesel from unrefined palm oil: comparison of methanolysis methods. J. Mol. Catal. B Enzym. 60, 106-112. doi:10.1016/j.molcatb.2009.04.004

Tang, S., Qin, C., Wang, H., Li, S., and Tian, S. (2011). Study on supercritical extraction of lipids and enrichment of DHA from oil-rich microalgae. J. Supercrit. Fluids 57, 44-49. doi:10.1016/j.supflu.2011.01.010

Tuccar, G., and Aydin, K. (2013). Evaluation of methyl ester of microalgae oil as fuel in a diesel engine. Fuel 112, 203-207. doi:10.1016/j.fuel.2013.05.016

Uduman, N., Qi, Y., Danquah, M. K., Forde, G. M., and Hoadley, A. (2010). Dewatering of microalgal cultures: a major bottleneck to algae-based fuels. J. Renew. Sust. Energy 2, doi:10.1063/1.3294480

Umdu, E. S., Tuncer, M., and Seker, E. (2009). Transesterification of Nannochloropsis oculata microalga's lipid to biodiesel on $\mathrm{Al} 2 \mathrm{O} 3$ supported $\mathrm{CaO}$ and MgO catalysts. Bioresour. Technol. 100, 2828-2831. doi:10.1016/j.biortech.2008. 12.027

Van den Hende, S., Vervaeren, H., and Boon, N. (2012). Flue gas compounds and microalgae: (Bio-)chemical interactions leading to biotechnological opportunities. Biotechnol. Adv. 30, 1405-1424. doi:10.1016/j.biotechadv.2012.02. 015

Vandamme, D., Foubert, I., Meesschaert, B., and Muylaert, K. (2010). Flocculation of microalgae using cationic starch. J. Appl. Phycol. 22, 525-530. doi:10.1007/ s10811-009-9488-8

Velasquez-Orta, S. B., Lee, J. G. M., and Harvey, A. P. (2013). Evaluation of FAME production from wet marine and freshwater microalgae by in situ transesterification. Biochem. Eng. J. 76, 83-89. doi:10.1016/j.bej.2013.04.003

Wang, B., Li, Y. Q., Wu, N., and Lan, C. Q. (2008). CO(2) bio-mitigation using microalgae. Appl. Microbiol. Biotechnol. 79, 707-718. doi:10.1007/s00253-0081518-y

Wang, H., Gao, L. L., Chen, L., Guo, F. J., and Liu, T. Z. (2013). Integration process of biodiesel production from filamentous oleaginous microalgae Tribonema minus. Bioresour. Technol. 142, 39-44. doi:10.1016/j.biortech.2013. 05.058

Weissman, J. C., Goebel, R. P., and Benemann, J. R. (1988). Photobioreactor design: mixing, carbon utilization, and oxygen accumulation. Biotechnol. Bioeng. 31, 336-344. doi:10.1002/bit.260310409
Xu, J., and Hu, H. H. (2013). Screening high oleaginous Chlorella strains from different climate zones. Bioresour. Technol. 144, 637-643. doi:10.1016/j.biortech.2013. 07.029

Xu, Y., Zheng, X., Yu, H., and Hu, X. (2014). Hydrothermal liquefaction of Chlorella pyrenoidosa for bio-oil production over Ce/HZSM-5. Bioresour. Technol. 156, 1-5. doi:10.1016/j.biortech.2014.01.010

Yang, C., Hua, Q., and Shimizu, K. (2000). Energetics and carbon metabolism during growth of microalgal cells under photoautotrophic, mixotrophic and cyclic light-autotrophic/dark-heterotrophic conditions. Biochem. Eng. J. 6, 87-102. doi:10.1016/S1369-703X(00)00080-2

Yang, S., Wang, J., Cong, W., Cai, Z., and Ouyang, F. (2004). Effects of bisulfite and sulfite on the microalga Botryococcus braunii. Enzyme Microb. Technol.35, 46-50. doi:10.1016/j.enzmictec.2004.03.014

Yoo, C., Jun, S.-Y., Lee, J.-Y., Ahn, C.-Y., and Oh, H.-M. (2010). Selection of microalgae for lipid production under high levels carbon dioxide. Bioresour. Technol. 101, S71-S74. doi:10.1016/j.biortech.2009.03.030

Yoo, J. J., Choi, S. P., Kim, J. Y., Chang, W. S., and Sim, S. J. (2013). Development of thin-film photo-bioreactor and its application to outdoor culture of microalgae. Bioprocess Biosyst. Eng. 36, 729-736. doi:10.1007/s00449-013-0898-2

Zhang, Y.-M., Chen, H., He, C.-L., and Wang, Q. (2013). Nitrogen starvation induced oxidative stress in an oil-producing green alga Chlorella sorokiniana C3. PLoS ONE 8:e69225. doi:10.1371/journal.pone.0069225

Zhou, W., Min, M., Li, Y., Hu, B., Ma, X., Cheng, Y., et al. (2012). A heterophotoautotrophic two-stage cultivation process to improve wastewater nutrient removal and enhance algal lipid accumulation. Bioresour. Technol. 110, 448-455. doi:10.1016/j.biortech.2012.01.063

Zittelli, G., Rodolfi, L., Bassi, N., Biondi, N., and Tredici, M. (2013). "Photobioreactors for microalgal biofuel production," in Algae for Biofuels and Energy, Vol. 5, eds M. A. Borowitzka and N. R. Moheimani (Springer: Dordrecht Heidelberg New York London), 115-131.

Conflict of Interest Statement: The authors declare that the research was conducted in the absence of any commercial or financial relationships that could be construed as a potential conflict of interest.

Received: 19 May 2014; accepted: 31 July 2014; published online: 19 August 2014. Citation: Zhang X, Rong J, Chen H, He C and Wang Q (2014) Current status and outlook in the application of microalgae in biodiesel production and environmental protection. Front. Energy Res. 2:32. doi: 10.3389/fenrg.2014.00032

This article was submitted to Bioenergy and Biofuels, a section of the journal Frontiers in Energy Research.

Copyright (c) 2014 Zhang, Rong, Chen, He and Wang. This is an open-access article distributed under the terms of the Creative Commons Attribution License (CC BY). The use, distribution or reproduction in other forums is permitted, provided the original author(s) or licensor are credited and that the original publication in this journal is cited, in accordance with accepted academic practice. No use, distribution or reproduction is permitted which does not comply with these terms. 